\title{
Rice Root-Associated Diazotrophic Community Succession is Driven by Growth Period Combined With Fertilization
}

\section{Zhongli Cui ( $\sim$ labc_7021@163.com )}

Nanjing Agricultural University https://orcid.org/0000-0001-8360-7411

\section{Xue Luo}

Nanjing Agricultural University

Xianfeng Ye

Nanjing Agricultural University

Wenhui Wang

Anhui Agricultural University

\section{Yang Chen}

Nanjing Agricultural University

\section{Chaonan Dong}

Nanjing Agricultural University

\section{Zhoukun Li}

Nanjing Agricultural University

\section{Yan Qiao}

Nanjing Agricultural University

\section{Yuqiang Zhao}

Nanjing Agricultural University

\section{Yan Huang}

Nanjing Agricultural University

\section{Wei Ran}

Nanjing Agricultural University

\section{Minghui Huan}

Microbial Research Institute of Liaoning Province

\section{Xiaodong Fang}

Guangzhou Hanyun Pharmaceutical Technology Co. Ltd.

\section{Jian Han}

Xinjiang Agricultural University

\section{Hui Cao}

Nanjing Agricultural University

\section{Research}

Keywords: Rice, Diazotrophs, Rhizosphere, Roots, Niche differentiation, Transcription level, nifH amplicon pyrosequencing, Network analysis

Posted Date: October 20th, 2020

DOI: https://doi.org/10.21203/rs.3.rs-92206/v1 
License: (c) (i) This work is licensed under a Creative Commons Attribution 4.0 International License. Read Full License 


\section{Abstract}

Background

Biological nitrogen fixation (BNF) and nitrogenous fertilizers are two crucial ways for nitrogen input in the rice paddy system. Little is known about the effect of nitrogenous fertilizers on root-associated diazotrophs. Here, we investigated the succession of total and active diazotrophs in rhizosphere soil and rice roots under four fertilization treatments (control, NPK, NPK + pig manure, and NPK + rice straw) during three key growth periods (tillering, heading and mature).

Results

The ${ }^{15} \mathrm{~N}$ isotope dilution experiment verified that root-associated diazotrophs could supply $\mathrm{N}$ for rice under low nitrogen nutrition by BNF (\%Ndfa=11.51). Niche differentiation of diazotrophs existed at the rhizosphere soil-root interface. At both DNA and RNA levels, growth period had stronger effects on the community composition of endophytic diazotrophs than rhizosphere diazotrophs. The Chao1 and Shannon indices of total endophytic diazotrophs dramatically increased at the vegetative stage, and underwent relatively minor changes at the reproductive stage. Furthermore, the community structures of total endophytic diazotrophs were more stabilized in the reproductive stage than the vegetative stage. The number of OTUs shared by rhizosphere soil and roots increased during rice growth. Compared with CK, NPK reduced the relative abundances of Pelobacter and increased the relative abundances of Azoarcus. Pig manure not only improved soil nutrients (OM, TN, TP, AN, AP and NO3-N), but reduced the effect of chemical fertilizers on the community composition of natural rhizosphere diazotrophs.

\section{Conclusions}

Growth period demonstrated a stronger influence on the root-associated diazotrophs than fertilization practices. The community structures of total endophytic diazotrophs were more stabilized in the reproductive stage than the vegetative stage, and the alpha-diversity indices and complex of network structures of endophytic diazotrophs increased at the vegetative stage. Replacing chemical fertilization with pig manure not only increased soil nutrients, but regulated rhizosphere diazotrophic community structures. Understanding the combined effects of growth period and fertilization on root-associated diazotrophs presents the basis towards the sustainable crop production.

\section{Background}

As a critical macronutrient, nitrogen $(\mathrm{N})$ often limits plant yields in the agricultural ecosystem [1]. Over the past several decades, chemical fertilizers increase crop production, however, nitrogen-use efficiency (NUE) in rice is only about 39\% [2] and excessive $\mathrm{N}$ causes soil acidification and environmental pollution [3]. Alternatively, BNF is an available and ecofriendly way to provide $\mathrm{N}$ for plants, which can reduce atmospheric dinitrogen to biologically available ammonium by nitrogen-fixing bacteria and archaea. Numerous Diazotrophs could colonize and reproduce in the bulk, rhizosphere soil and rice tissues [4-7], and increased crop productivity through BNF [8], producing antimicrobials [9], and improving abiotic stress tolerance [10].

Vegetation type [11], plant genotype [12] and soil physicochemical property [13] influenced the abundance, diversity and community composition of diazotrophs. However, effects of these factors on diazotrophic composition and nitrogenfixing capacity were inconsistent in different ecosystems. For example, the application of $\mathrm{N}$ fertilizer or $\mathrm{N}$ fertilizer plus pig manure reduced the relative abundant of Bradyrhizobium [14-15], but Hu et al. [16] indicated that Bradyrhizobium was significantly increased by $\mathrm{N}$ fertilizer application. However, there are few agricultural experiments comparing fertilization management, especially replacing chemical fertilization by manure, on the rhizosphere and endophytic diazotrophic diversity and community composition in the paddy field.

Page $3 / 40$ 
The establishment of rhizosphere and root microbiota is a dynamic process and plants participate in and regulate this process [17]. The composition of root exudates changes dynamically across developmental stages, and these chemical compounds are used to attract and enhance the root colonization of beneficial microbes [17-19]. For example, legumes secret signal molecules, like flavonoids [7] and nodule-specific cysteine-rich (NCR) peptides [20], which influence the colonization and terminal differentiation of nitrogen-fixing bacteria. Previous studies had shown that rice root-associated microbiota dramatically varied during the vegetative stage and stabilized during the reproductive stage [21-22]. However, limited researches characterized the community succession of rice root-associated diazotrophs during rice cultivation, especially for the endophytic diazotrophs. Moreover, the existence of diazotrophs didn't mean that they could fix nitrogen actively [23] and their nitrogenase activities could be different [24-25]. Given above, it is noteworthy that the response of nitrogen-fixing microorganisms to fertilization management and growth period at the transcript level.

Here, high-throughput sequencing of the highly conserved nifH gene were used to explore the diversity and community structures of the total and active rhizosphere and endophytic diazotrophs under different fertilization treatments (CK, NPK, NPKM and NPKS). We sampled rhizosphere soil and rice roots in a long-term field experiment located in Jintan, China during three key rice growth periods (tillering, heading and mature stages) in 2015 and 2016 (Additional file 1: Table S1). Objectives of our research are as follows: (1) to verify the promotion of diazotrophs in the rice root grinding fluid on rice growth; (2) to compare the community of rhizosphere and endophytic diazotrophs at the DNA and RNA levels in the process of rice cultivation, and select root-enriched diazotrophs; (3) to evaluate effects of growth period and fertilization management on soil physicochemical properties, diversity, and composition of total and active diazotrophs; (4) to study the successional patterns of rhizosphere and endophytic diazotrophs.

\section{Results}

\section{BNF plays an important role in $\mathrm{N}$ supply during rice growth}

The rice yields of three fertilization treatments (NPK, NPKM, NPKS) were significantly higher than CK, while the yields of CK kept consistent since 2015 (Fig. 1a). Non-symbiotic BNF supplied 37.32\% crop N for rice [26]. Thus, we inferred that nitrogen-fixing bacteria of CK played an important role to maintain rice production. The ${ }^{15} \mathrm{~N}$ isotope dilution method was used to evaluate the contribution of endophytic diazotrophs in the nitrogen nutrition supply for rice growth (Table 1). The root length, plant height and fresh weight of rice of $\mathrm{C}_{20}$ and $\mathrm{T}_{20}$ had no significant difference but were significantly lower than $\mathrm{T}_{10}$. The $\mathrm{N}$ concentration among the three treatments had no significant difference, but $\delta_{15} \mathrm{~N}$ of $\mathrm{C}_{20}(33.26 \% \pm 1.10 \%)$ and $\mathrm{T}_{20}(33.85 \% \pm 0.25 \%)$ were significantly higher than $\mathrm{T}_{10}(29.43 \% \pm 0.49 \%)$. It certified that endophytic nitrogen-fixing bacteria could supply $\mathrm{N}$ for rice by BNF under low nitrogen nutrition (\%Ndfa=11.51).

Twenty-five isolates isolated from surface-sterilized rice roots including Proteobacteria (80\%), Firmicutes (12\%) and Actinobacteria (8\%) (Additional file 2: Table S2). The nifH gene fragments were amplified from five isolates, then their nitrogenase activities were measured by ARA (Additional file 3: Table S3). The nitrogenase activity of strain BV6 (Burkholderia) was highest $(25.71 \mu \mathrm{mol} / \mathrm{h} / \mathrm{ml})$.

\section{The diversity of total rhizosphere and endophytic diazotrophs were shaped by growth period, year and fertilization}

Illumina sequencing was performed to investigate the community compositions of rhizosphere and endophytic diazotrophs and their response to different fertilization managements in different growth periods. 318 samples collected from the field (120 rhizosphere soil DNA samples, 119 root DNA samples, 48 rhizosphere soil RNA samples and 31 root RNA samples) were sequenced, and after normalization, each sample had 22552 sequences. These sequences were clustered into 706 operational taxonomic units (OTUs) at $90 \%$ identity. 
For alpha diversity analyses, richness index (Chao1), evenness index (Shannon) and phylogenetic diversity index (PD) of rhizosphere diazotrophs were significantly higher than endophytic diazotrophs at the DNA level (Additional file 4: Table S4), which was consistent with the results of rarefaction curves (Additional file 5: Figure S1). Interestingly, total rhizosphere diazotrophs had the highest a-diversity at the tillering stage, while total endophytic diazotrophs had the lowest a-diversity at this stage (Additional file 4: Table S4). The effects of growth period on all tested a-diversity indices were statistically significant, but fertilization only had significant effects on the evenness index (Table 2). For soil and root DNA samples, almost all a-diversity indices of diazotrophs among four fertilization treatments (CK, NPK, NPKM and NPKS) had no significant difference (Additional file 6: Table S5, Additional file 7: Table S6).

The phylogenetic trees of 50 dominant OTUs based on the sequences of nifH genes were generated (Fig. 2, Additional file 8: Figure S2). The relative abundances of dominant OTUs of total rhizosphere diazotrophs were notably different from total endophytic diazotrophs. Moreover, the whole community structure of total rhizosphere diazotrophs was notably different from and more stable than total endophytic diazotrophs (Additional file 9: Table S7, Fig. 1b). We visualized and quantified the differences between diazotrophic communities ( $\beta$-diversity) using non-metric multidimensional scaling (NMDS) and permutational multivariate analysis of variance (PERMANOVA). The growth period was a primary driver of the total rhizosphere $\left(R^{2}=0.22, P<0.001\right)$ and total endophytic diazotrophic $\beta$-diversity $\left(R^{2}=0.33, P<0.001\right)(F i g .1 c-d$, Additional file 10: Figure S3a-b, Table 2), revealing a stronger temporal effect on total endophytic diazotrophs than total rhizosphere diazotrophs. However, total rhizosphere diazotrophs were more sensitive to the year and fertilization management $\left(R^{2}=0.19\right.$ and $\left.0.11, P<0.001\right)$ than total endophytic diazotrophs $\left(R^{2}=0.06\right.$ and $\left.0.05, P<0.001\right)$. Year, growth period and fertilization management showed significant interactions in pairs.

\section{Taxonomic composition and fertilizer-sensitive taxa}

Fourteen phyla were determined by pooling the nifH sequences, and Proteobacteria was the predominant phylum, contributed approximately $57.0 \%$ and $76.1 \%$ of soil and root samples, respectively (Additional file 11: Figure S4). The top three classes of soil samples were Alphaproteobacteria (25.29\%), Deltaproteobacteria (20.65\%) and Betaproteobacteria (8.83\%) (Fig. 1e, Additional file 12: Figure S5a). However, Betaproteobacteria (34.95\%), Gammaproteobacteria (18.51\%) and Alphaproteobacteria (15.37\%) were the three dominant classes of root samples. At the genus level, Bradyrhizobium (24.80\%), Geobacter (7.72\%) and Burkholderia (5.71\%) were the top three genera of soil samples (Additional file 12: Figure S5b-c), but for root samples, they were Burkholderia (26.74\%), Thiorhodospira (8.88\%) and Bradyrhizobium (8.25\%).

In these four cluster trees (Fig. 1e, Additional file 12: Figure S5), soil DNA samples and root DNA samples were divided into two clusters, and samples from the same growth period were frequently clustered together except for soil samples in 2016. However, PERMANOVA and ANOSIM suggested that the growth period significantly affected the total rhizosphere diazotrophic communities in 2016 (data not shown). Generally, the communities of either total rhizosphere or endophytic diazotrophs of NPK and NPKS treatments were clustered together, and they were separated from CK and NPKM treatments (Fig. 1e, Additional file 12: Figure S5a). Furthermore, the soil samples of CK were quite different from the other three fertilization treatments, and differences between CK and NPKM were smaller than CK and NPK or CK and NPKS (Additional file 13: Table S8). We noted that the relative abundances of Pelobacter of NPKM were lower than that of CK and higher than that of NPK, but Azoarcus was the opposite (Additional file 14: Figure S6). Furthermore, for Bradyrhizobium, Geobacter, Heliobacterium, Rubrivivax and Desulfomonile, their abundance of of NPKM were between that of CK and NPK at most sampling points.

The rhizosphere soil physicochemical indices OM, TN, TK, TK, AN, AP, AK, pH, NO3-N and NH4-N were tested (Additional file 15: Table S9). Soil pH value of CK was highest among four fertilization treatments. NPKM increased the content of organic matter (OM), total N (TN), total P (TP), available N (AN) and available $P(A P)$ and NO3-N. Fertilization management, year and period had significant effects on all tested physicochemical parameters $(P<0.01$, Additional file 16: Table S10), except that the period had no significant effects on TN and NH4-N ( $>0.05)$. Most rhizosphere and endophytic 
diazotrophic a-diversity indices had negative correlation with TP and AN at six sampling points (Additional file 17: Table S11). The Mantel test showed that AK, TK and NH4-N were significantly negatively correlated with the community structures of total rhizosphere and endophytic diazotrophs (Additional file 18: Table S12). Correlation analysis showed that $\mathrm{pH}$ had a significant positive correlation with Pelobacter, but had a significant negative correlation with Thermodesulfovibrio in rhizosphere soil (Additional file 19: Figure S7).

\section{The community structures of total endophytic diazotrophs were more stabilized in the reproductive stage than the vegetative stage}

The similarity distances (1-Bray dissimilarity) of diazotrophic community structures among three rice growth periods were calculated at each fertilization treatment (Fig. 3a-b). For root samples, the similarity distances between the tillering and heading stages (red nodes) were higher than the tillering and mature stages (green nodes), but lower than the heading and mature stages (blue nodes). However, this trend was not observed in soil samples.

Tracking diazotrophic community changes at the class level revealed that many classes showed distinct temporal dynamics in root samples (Fig. 3c-d). For example, Alphaproteobacteria and Deltaproteobacteria enriched as time went on, but Betaproteobacteria decreased. The endophytic diazotrophic abundance of "others" (mainly unclassified taxa) remarkably increased, and was close to rhizosphere diazotrophs at the mature stage. The abundance of shared OTUs between soil and root samples in soil samples (Pink flows) apparently increased during rice cultivation, but slightly decreased in root samples.

The linear discriminate analysis (LDA) effect size (LEfSe) was used to identify the distinguishing diazotrophs during different growth periods in paddy soil and rice roots [27]. The numbers of the discriminating taxa of rhizosphere diazotrophs, whose LDA scores between different growth periods greater than 2, were 172 and 96 in 2015 and 2016, and of the endophytic diazotrophs were 149 and 97 (data not shown). The discriminating genus significantly increasing at the same sampling period over two years were filtered and heatmaps were drawn to demonstrate more particular information of the responses of these genera to the growth period (Fig. 3e-f). For the rhizosphere soil samples, the relative abundances of Treponema, Chloroherpeton, Paludibacter, Coraliomargarita and Desulfobulbus were significantly higher at the tillering stage than at the heading and mature stage (Fig. 3e), and they were correlated positively with AK (Additional file 19: Figure S7a-b); the relative abundances of Oscillatoria, Cyanothece and Coleofasciculus were significantly higher at the heading stage, and Oscillatoria was correlated negatively with NO3-N; the relative abundances of Heliobacterium, Sinorhizobium and Frankia were significantly higher at the mature stage, and they were correlated positively with NO3-N. For root samples, the relative abundance of Tolumonas was significantly higher at the tillering stage than at the other stages (Fig. 3f); the relative abundances of Thiorhodospira, Sulfurospirillum, Pelosinus and Selenomonas were significantly higher at the heading stage, and Thiorhodospira was correlated negatively with $\mathrm{pH}$ and NO3-N; the relative abundance of Rhizobium, Desulfovibrio, Geobacter, Frankia and Acetobacterium were significantly higher at the mature stage, and they were correlated negatively with AK (Additional file 19: Figure S7c-d).

\section{Diversity and community structures of active nitrogen-fixing bacteria}

Consistent with the total root-associated diazotrophs, the community structures of active rhizosphere diazotrophs were notably different from active endophytic diazotrophs (Additional file 9: Table S7); growth period was a primary driver of the active rhizosphere $\left(R^{2}=0.15, P<0.001\right)$ and active endophytic diazotrophic $\beta$-diversity $\left(R^{2}=0.17, P<0.001\right)$; fertilization management had a higher effect on the $\beta$-diversity of active rhizosphere diazotrophic $\left(R^{2}=0.14, P<0.001\right)$ than endophytic diazotrophs $\left(R^{2}=0.10, P>0.05\right)$ (Additional file 20: Table S13, Additional file 10: Figure S3c-d). The rhizosphere diazotrophic community structures of CK and NPKM had no significant difference, and both of them had significant differences with the rhizosphere diazotrophic community structures of NPK and NPKS. (Additional file 13: Table S8). The relative abundances of Geobacter of NPKM were higher than that of CK and lower than that of NPK in soil RNA samples 
(Additional file 14: Figure S6). Furthermore, TP, and AN, and had negative correlation with a-diversity indices of active rhizosphere and endophytic diazotrophs, and NH4-N and NO3-N had significant negative correlation with active rhizosphere diazotrophs (Additional file 17: Table S11). The Mantel test showed that TK, AN, AP, pH and NO3-N were significantly correlated with the community structures of active rhizosphere diazotrophs, and NO3-N had a significant correlation with the community structures of active endophytic diazotrophs (Additional file 18: Table S12).

Richness, Evenness and PD indices of all DNA samples were higher than corresponding RNA samples (Additional file 4: Table S4). The $\beta$-diversity of the total and active diazotrophic communities was investigated as well (Additional file 10: Figure S3e). The soil DNA samples clustered together, whereas the soil RNA samples, root DNA samples and root RNA samples were more dispersed. To compare their aggregation difference, the similarities ( $Z$ scores) in between-group diazotrophic community composition were visualized in bar plots. Z scores of the soil RNA samples, root DNA samples and root RNA samples had not significant differences but they were significantly lower than the soil DNA samples (Fig. 4a).

The rhizosphere DNA and RNA samples separated on the cluster tree (Fig. 4c), but root DNA samples and their corresponding RNA samples frequently clustered together (Fig. 4d). The correlation coefficient of the total and active diazotrophic communities in soil (Spearman correlation: $r=0.244, \mathrm{P}<0.05$ ) was slightly smaller than that in roots at the OTU level (Spearman correlation: $r=0.271, P<0.05$ ). In Fig. $4 b, Z$ scores of the soil DNA and RNA samples at the heading stage were highest, but there was no significant differences between $Z$ scores of the soil DNA and RNA samples at tillering and mature stages, and Z scores of the root DNA and RNA samples at heading and mature stages.

The abundance changes of diazotrophs at the RNA and DNA levels were calculated in the rhizosphere soil and rice roots (Additional file 21: Figure S8a-b). Burkholderia, Anaeromyxobacter, Bradyrhizobium and Pelobacter predominated in the total and active rhizosphere diazotrophic communities. NifH gene expressions in Burkholderia and Anaeromyxobacter were somewhat higher than that of the total rhizosphere diazotrophic community, whereas nifH gene expressions in Bradyrhizobium and Pelobacterwere opposite. Burkholderia, Azoarcus, Thiorhodospira and Bradyrhizobium predominated in the total and active endophytic diazotrophic communities. Growth period and fertilization appreciably affected the nifH gene expressions of endophytic diazotrophs. For instance, the abundance changes of Azoarcus at the RNA and DNA levels at the heading and mature stage were the opposite. The abundance changes of Burkholderia, Thiorhodospira and Bradyrhizobium at the RNA and DNA levels of CK and the other three fertilization managements were the opposite. Due to high between-sample variations, which might be caused by environmental differences, there was a few or no statistically significant difference of diazotrophic abundance at the RNA and DNA level in the soil or roots.

\section{Root-enriched nitrogen-fixing bacteria}

To investigate the distribution of nitrogen-fixing bacteria in rice roots and rhizosphere soil, the relative abundances of 39 dominant genera in these two niches were compared by the STAMP software. The size of the bubbles in the chart (Fig. 5) represents the relative abundance of 39 dominant genera in rice root samples, and the color of the bubbles represents the difference between the square root of the relative abundances of these genera in the roots and soil.

At the DNA and RNA levels, the relative abundances of Thiorhodospira, Rhizobium and Burkholderia in all root samples at three growth periods were almost significantly higher than that in corresponding soil samples $(\mathrm{P}<0.05)$; the relative abundances of Paludibacter, Magnetospirillum, Clostridium and Rhodospirillum in root samples at the heading and mature stages were significantly higher than that in corresponding soil samples; the relative abundances of Sulfurospirillum at the heading stage, Azoarcus and Frankia at the mature stage in root samples were significantly higher than that in corresponding soil samples. However, Bradyrhizobium, Pelobacter, Heliobacterium, Geobacter and Anaeromyxobacter had significantly higher relative abundance in the rhizosphere soil than that in rice roots.

\section{Co-occurrence patterns of total and active root-associated diazotrophs}


Co-occurrence networks were built to explore potential interactions and niche-sharing of diazotrophs in paddy soil and rice roots during three key growth periods (Fig. 6, Additional file 22: Figure S9). In each of these networks, nodes represent OTUs (relative abundance $>0.01 \%$ ) and edges represent significant co-occurrence relationships (Spearman $|r|>0.65$ and $\mathrm{P}<0.01$ ). Topological properties of co-occurring network were calculated (Additional file 23: Table. S14). Overall, the ecological networks of rhizosphere and endophytic diazotrophs had different network sizes and degree of connectivity, and showed distinct time related successions at three key rice growth periods. Consistent with the a-diversity analyses (Additional file 4: Table. S4), networks of rhizosphere diazotrophs were more complex in comparison with endophytic diazotrophs. For instance, the numbers of nods $(237.5 \pm 51.64)$ and edges $(1444 \pm 840.69)$ in soil DNA samples were greater than the numbers of nods $(117.67 \pm 48.55)$ and edges $(201.83 \pm 136.28)$ in root DNA samples. Moreover, soil RNA samples had greater numbers of nods $(224.67 \pm 43.04)$ than root RNA samples $(150 \pm 36.77)$, and had greater numbers of

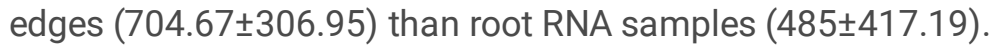

Compared with networks at the tillering stage, the rhizosphere and endophytic diazotrophic assemblages formed larger and more complex networks at the heading and mature stages. Networks of total rhizosphere and endophytic diazotrophs at the heading and mature periods exhibited similar network topological structures (nodes, links, average path distance, average clustering coefficient, average degree and modularity) in 2016. However, for active diazotrophs, soil RNA network at the mature stage was most complex, and root RNA network at the heading stage was more intricate. The percent of positive correlations in total rhizosphere diazotrophic networks $(57.31 \% \pm 3.63 \%)$ was much less than that in total endophytic diazotrophic networks (83.05\% $\pm 7.52 \%)$, active rhizosphere diazotrophic networks $(88.81 \% \pm 9.22 \%)$ total endophytic diazotrophic networks (88.43\% $15.64 \%)$.

\section{Discussion}

Rice is the dominant crop in the middle and lower reaches of the Yangtze River Basin in China and produces more than $65 \%$ rice yield of the total country. Rice productivity is usually limited by nitrogen [28]. Nitrogenous fertilizer and BNF to a large extent raise rice productivity and make up for the depletion of soil nitrogen nutrient stocks caused by crop uptake [26]. Fertilization management [29-31] and growth period [32-33] varied the diazotrophic community compositions in the agricultural ecosystem. However, the combined effects of fertilization and growth period on diazotrophic communities in the paddy field still remain largely unknown. In this study, we investigated the combined effects of fertilization and growth period on the community composition of rhizosphere and endophytic diazotrophs in the paddy ecosystem at the DNA and RNA levels using amplicon sequencing. The strength of this experiment is that revealing niche differentiation of diazotrophs and including the effects of fertilization and temporal changes into the experimental design.

\section{Different responses of rhizosphere and endophytic diazotrophs}

Rice root exudates induce a chemotactic response for rhizosphere [18] and endophytic bacteria [34], and defense responses of plants limit bacterial invasion [35]. Thus, specific bacteria can penetrate root tissues and colonize in plants [36]. The OTU richness indices of endophytic diazotrophs were more variable than rhizosphere diazotrophs, as depicted by the rarefaction curves (Additional file 5: Figure S1). It is probably caused by sporadic and non-uniform colonization of endophytic diazotrophs in the roots [37]. The community composition of rhizosphere and endophytic microbiome were different in various plants [36,38-40]. In this present study, the community compositions of rice rhizosphere diazotrophs were significantly different from rice endophytic diazotrophs at the DNA and RNA levels (Additional file 9: Table S7), suggesting that rice roots represent a unique niche for diazotrophic communities. Phylogenetic analysis showed that Alphaproteobacteria (25.29\%) was the dominant class and Bradyrhizobium (24.8\%) was the dominant genus in rice rhizosphere soil. Similar observations were reported in rice bulk soil [16] [41]. For root samples, Betaproteobacteria (34.95\%) was the dominant class in rice roots [42-43]. The previous study has reported endophytic diazotrophs were 
dominated by Gammaproteobacteria (66-98\%) before flooding, whereas after flooding Betaproteobacteria was the dominant class (26-34\%) [44].

The rhizosphere diazotrophic communities were more diverse than the endophytic diazotrophic communities at the DNA and RNA levels (Additional file 4: Table S4) [36,39], and the community structures of rhizosphere diazotrophs were notably different from endophytic diazotrophs (Additional file 9: Table S7) [40,45]. Moreover, compare with year and fertilization management, growth period (temporal variations) was the dominant factor affecting the community composition of rhizosphere and endophytic diazotrophs (Table 2, Additional file 20: Table S13). Previous studies had reported that the diversity of free-living diazotrophic and total bacterial populations were more sensitive to temporal and seasonal effects than fertilization management in agricultural soil [46]. Notably, growth period had a higher significant effect of the endophytic diazotrophic communities than that of the rhizosphere diazotrophic communities, but fertilization management had a stronger effect on the community composition of rhizosphere diazotrophs than endophytic diazotrophs. Taken together, growth period, year, and fertilization affect soil and root diazotrophic communities differently.

We also found some root-enriched nitrogen-fixing bacteria whose abundances in roots were significantly higher than that in soil (Fig. 5). Thiorhodospira, Rhizobium and Burkholderia were root-enriched diazotrophs at three growth periods, and Paludibacter, Magnetospirillum, Clostridium and Rhodospirillum were root-enriched diazotrophs at the heading and mature stages. They occupied high relative abundance in rice roots at the DNA $(46.29 \% \pm 14.93 \%)$ and RNA $(47.77 \%$ $\pm 13.01 \%$ ) levels. Burkholderia and Rhizobium were common plant endophytic diazotrophs [47-49], and some strains of these genera have been used as plant growth-promoting bacteria (PGPB) and biocontrol bacteria [50-52]. Besides, Burkholderia sp. BV6, Burkholderia sp. CJ42 and Rhizobium sp. CJ54 were isolated from surface-sterilized rice roots in this work (Additional file 2: Table S2). Sulfurospirillum is a reductively dechlorinating bacterium [53]. Thiorhodospira is an purple sulfur bacterium, but its nitrogenase activity has not been tested [54]. It is widely admitted that endophytic diazotrophs are capable to fix $\mathrm{N}$ more efficiently than the rhizosphere or rhizoplane diazotrophs [55], so we speculate that these root-enriched diazotrophs play an important role for rice growth and development in the whole life cycle of rice.

\section{Shifts of the total community composition of rhizosphere and endophytic diazotrophs during rice growth}

Previous work showed that temporal variations in the abundance and diazotrophic community composition, but these studies were carried out either with low resolution detection methods or ignoring endophytic diazotrophs [32-33,56-57]. We studied the structural variability in the root-associated diazotrophs during a rice growing season. Our research demonstrated that the community structures of total endophytic diazotrophs varied dramatically during the vegetative stages and stabilized at the reproductive stage (Fig. 3b), which was consistent with the results of rice root microbiota by 16S rRNA gene amplicons sequencing [21-22]. Additionally, the richness, evenness and PD indices of total endophytic diazotrophs significantly increased at the vegetative stage, but the a-diversity indices of total rhizosphere diazotrophs had no significant changes (Additional file 4: Table S4). Thus, we deduced that abundant diazotrophs recruited from the paddy soil colonize and reproduce in rice roots at the vegetative stage, which caused large changes in diazotrophic community structure. We see support for this idea as the proportion of nitrogen-fixing bacteria shared by soil and root samples increased clearly over time, and the percentage of unclassified diazotrophs in roots was close to that in soil (Fig. $3 e)$. Considering that root exudation increased with rice growth until panicle initiation and decreased from the flowering period to the maturing stage [58], the community succession of rice endophytic diazotrophs is probably driven by root exudation. However, further studies are needed to investigate the regulation mechanism of root exudates on the endophytic diazotrophic community. Moreover, when applying nitrogen-fixing bacteria as bio-fertilizers, it should be taken into account whether they could colonize efficiently in the roots at a particular time.

\section{Pig manure application maintained the community composition of natural rhizosphere diazotrophs}


Nitrogen deficiency promotes root growth, but decreases shoot biomass, shoot and root nitrogen content [59-60]. Furthermore, the efficiency of BNF is promoted with low $\mathrm{N}$ concentration [61], but rapidly reduced or even inhibited under a high concentration of ammonium [62]. The ${ }^{15} \mathrm{~N}$ isotope dilution experiment verified that low nitrogen nutrition promoted elongation of rice roots, and rice inoculated with a mixture of endophytic diazotrophs obtain a higher level of BNF contribution with a low $\mathrm{N}$ content (Table 1).

Previous researches showed that applying chemical or organic fertilizers decreased the diversity of dominant diazotrophs [31], but we found that fertilization management was inconsequential to the a-diversity indices of total diazotrophs in rhizosphere soil and rice roots (Additional file 6: Table S5, Additional file 7: Table S6), which was consistent with Wakelin and Ogilvie's observations [63-64]. According to the correlated analysis, AN and TP had significantly negative correlation with a-diversity indices of total rhizosphere diazotrophs (Additional file 17: Table S11).

Given that the $\beta$-diversity of rhizosphere diazotrophs were more affected by fertilization than that of endophytic diazotrophs (Table 2, Additional file 20: Table S13), we focused on the effect of fertilization on rhizosphere diazotrophs. Compared with NPK and NPK + rice straw (NPKS), the rhizosphere diazotrophic community of NPK + pig manure (NPKM) and control (CK) had higher similarities at the DNA and RNA levels (Additional file 13: Table S8). Thus, the application of pig manure not only increased soil nutrients (OM, TN, TP, AN, AP and NO3-N) (Additional file 15: Table S9) [65], but reduced the effect of chemical fertilization on the natural rhizosphere diazotrophic community structure.

\section{Active rhizosphere diazotrophic communities are less diversity but more divergent than total hizosphere diazotrophic communities}

We used RNA-derived nifH gene Illumina sequencing to elucidate the accurate diazotrophic community structure and characterize the nifH expression profile of rice root-associated diazotrophs. The a-diversity indices of rhizosphere and endophytic diazotrophs in the DNA samples were less than their corresponding RNA samples (Additional file 4: Table S4). The community structures of total and active diazotrophs in soil or roots were had evident deviations [66], and the community structures of active rhizosphere diazotrophs were more volatile than that of total rhizosphere diazotrophs (Fig. 4a, Additional file 10: Figure S3e). This is consistent with previous observations that seasonal variation and management practices had more effect on the active diazotrophs than total diazotrophs in bulk and rhizosphere soil [29,67-68]. Our results suggest that AN, TP, NH4-N and NO3-N had significant negative correlation with a-diversity indices of active rhizosphere diazotrophs (Additional file 17: Table S11). Our work extend previous studies by specifically characterizing the distribution and transcriptional activity of active root-associated diazotrophs in the paddy field.

\section{The temporal dynamics of root-associated diazotrophic networks}

Habitat heterogeneity influenced the bacterial [69] and fungal [70] network interactions. In our work, rhizosphere diazotrophs formed larger and more complex networks than endophytic diazotrophs at the DNA and RNA levels. The strong host-specific screening effect is imposed by plants on soil microbes, resulting in that only specific microorganism can colonize roots [71]. Previous alpha diversity analyses showed that the richness and evenness indices of rhizosphere diazotrophs were higher than endophytic diazotrophs (Additional file 4: Table S4), meaning number of OTUs in soil was greater than that in roots. The percent of positive correlations in total rhizosphere diazotrophic networks were lowest in all networks, meaning that total rhizosphere diazotrophs had more competitive relationships than total endophytic diazotrophs, active rhizosphere diazotrophs and endophytic diazotrophs (Fig. 6).

\section{Conclusions}

This study provides a comprehensive understanding of the combined effects of growth periods and fertilization management on the diversity, composition and co-occurrence network of root-associated diazotrophs in the paddy field 
during the whole growth period. We proved that the structural variability of rhizosphere diazotrophs is much lower than that of the endophytic diazotrophs, and growth period and fertilization management are undeniably important factors affecting nitrogen-fixing bacteria community. Specific diazotrophs appear to be recruited from the paddy soil to colonize and reproduce in rice roots during rice growth. Furthermore, the community structures of total endophytic diazotrophs were more stabilized in the reproductive stage than the vegetative stage. Follow-up studies need to investigate the effects of plant age, developmental progression, climatic variations and cropping management on diazotrophs in the paddy system, reveal the colonization process of diazotrophs, and further deepen our knowledge of root-rhizosphere soildiazotrophs interactions.

\section{Methods}

\section{Field experimental design}

The field experiment is located in Jintan City, Jiangsu Province, China $\left(31^{\circ} 39^{\prime} \mathrm{N}, 119^{\circ} 28^{\prime} \mathrm{E}\right)$. The soil type is classified as typical Wushan soil, with a long-term annual rotation of winter wheat (Triticum aestivum L.) and summer rice (Oryza sativa L.). The fertilization experiment started in 2010 using a random block design (Additional file 1: Table S1). Here, we chose four fertilization treatments including no fertilization (CK), 100\% chemical fertilizers (NPK), 50\% chemical fertilizers plus $6000 \mathrm{~kg} / \mathrm{ha}$ pig manure (NPKM), 100\% chemical fertilizers plus $8000 \mathrm{~kg} / \mathrm{ha}$ crop straw (NPKS). 100\% chemical fertilizers contained urea: $300 \mathrm{~kg} / \mathrm{ha}, \mathrm{P}_{2} \mathrm{O}_{5}: 120 \mathrm{~kg} / \mathrm{ha}$ and $\mathrm{K}_{2} \mathrm{O}: 100 \mathrm{~kg} / \mathrm{ha}$. All $\mathrm{P}, \mathrm{K}$, manure fertilizers and crop straw were applied as basal fertilizers before planting, whereas $\mathrm{N}$ fertilizers were used as basal fertilizers and supplementary fertilizers (basal fertilizers: tillering supplementary fertilizers: panicle supplementary fertilizers $=4: 3: 3$ ).

\section{Hydroponic experiment}

Fresh rice roots were sampled from the experimental field, and surface-sterilized with $75 \%$ ethanol for 1 min and $1 \%$ $\mathrm{NaClO}$ for $4 \mathrm{~min}$. Then the roots were ground with a mortar, and made into the rice root grinding fluid. Oryza sativa seeds were sterilized with $5 \%$ sodium hypochlorite for $1 \mathrm{~h}$ and then germinated. After 16 days, roots of rice seedlings were sampled and surface-sterilized, then rice root DNA was extracted. The endophytic diazotrophs was undetected using polF/polR primers [72]. The remaining 36 rice seedling (three-leaf stage) were divided into three groups. Thereinto, the $T_{10}$ and $\mathrm{T}_{20}$ treatments were inoculated by soaking roots in the rice root grinding fluid for $12 \mathrm{~h}$ at room temperature, and the excess inoculum was washed off with tap water. Seedlings of the control group $\left(\mathrm{C}_{20}\right)$ were soaked using autoclaved root grinding fluid. Next, all rice seedlings were transferred into the $5 \mathrm{~L}$-beakers and each beaker had two seedlings. They were cultured in the Yoshida's culture solution [73] with some modification. The concentration of ${ }^{15} \mathrm{~N}$-labeled $\left(\mathrm{NH}_{4}\right)_{2} \mathrm{SO}_{4}(50$ atom\% excess) of $\mathrm{C}_{20}$ and $\mathrm{T}_{20}$ treatments was $20 \mathrm{ppm}$, while of $\mathrm{T}_{10}$ was $10 \mathrm{ppm}$. The nutrient solution was changed every five days and $\mathrm{pH}$ remained 5.5-6.5 throughout the experiment.

After planting for 62 days, fresh weight, root length and plant height were measured. Destructive sampling of the whole plant was undertaken for determination of total $\mathrm{N}$ content and ${ }^{15} \mathrm{~N}$ concentration. The 12 seedlings were divided into three groups, and every group was dried in forced ventilation oven at $60^{\circ} \mathrm{C}$ for $6-8 \mathrm{~h}$, grinded and sieved $(0.25 \mathrm{~mm})$. Total $\mathrm{N}$ of the dry matter was determined using Kjeldahl digestion. ${ }^{15} \mathrm{~N}$ concentration was measured by Finnigan-MAT-251 mass spectrometer (Bremen, Germany) in the institute of Soil Science, Chinese Academy of Sciences, and the precision is \pm $0.20 \%$. The percentage of $\mathrm{N}$ derived from the atmosphere by BNF (\% $\mathrm{Ndfa}$ ) was calculated according to the equation: \% $N d f a=\left[1-R_{t} / R_{c}\right] \times 100 . R_{t}$ is the ${ }^{15} \mathrm{~N} /$ total $N$ ratio of the treatment, and $R_{S}$ is the ${ }^{15} \mathrm{~N} /$ total $N$ ratio of control.

\section{Endophytic diazotrophs isolated from rice roots}

Ten-fold serial dilutions of the rice root grinding fluid mentioned above were plated on YMA or Döbereiner's N-free media. After 3-5 d of incubation, isolates with different morphology were transferred and streaked on corresponding agar plates. 
25 strains were purified and their genome DNA were extracted with the TIANamp Bacteria DNA kit (TIANGEN) following the protocol. Their 16S rRNA and nifH gene were amplified by PCR using 27F/1492R and polF/polR primers. PCR products were ligated into pMD19-T-Simple Vector (TaKaRa, Dalian, China), sequenced, and identified their closest phylogenetic relatives [74]. Nitrogen fixation activity was measured using the modified ARA [75]. The isolates were cultivated in semisolid Döbereiner's media in sterilized test tubes, and a final concentration of $1 \%$ acetylene was added after growth for 2 days at $30^{\circ} \mathrm{C}$. The concentration of ethylene was detected $24 \mathrm{~h}$ later. Non-inoculated test tubes were used as negative controls and every isolate had three replicates. Ethylene was measured with a gas chromatograph (Shimadzu GC-2010, Kyoto, Japan) equipped with a Porapak N packed column and a flame ionization detector (FID). The injector, detector and oven temperatures were $180^{\circ} \mathrm{C}, 220^{\circ} \mathrm{C}$ and $100^{\circ} \mathrm{C}$, respectively. The carrier gas was $\mathrm{N}_{2}$ (highest available purity) at a flow rate of $10 \mathrm{ml} / \mathrm{min}$, and the supply of $\mathrm{H}_{2}$ and air for the FID were 30 and $300 \mathrm{ml} / \mathrm{min}$, respectively. The retention time of ethylene was $5.23 \mathrm{~min}$, and the retention time of acetylene was $7.15 \mathrm{~min}$. Isolates were cultured in YMA medium with or without $0.5 \mathrm{~g} / \mathrm{I}$ Trp for $24 \mathrm{~h}$. After centrifugation, the IAA production of the supernatant was determined by Salkowski reagent $\left(12 \mathrm{~g} \mathrm{FeCl}_{3}\right.$ per liter in $7.9 \mathrm{M} \mathrm{H}_{2} \mathrm{SO}_{4}$ ) [76]. CAS solution was used for the quantitation of siderophore production of supernatants [77]. Isolations were inoculated on the solid National Botanical Research Institute's phosphate growth medium (NBRIP) and their soluble phosphorus circles were observed.

\section{Sample collection of the field experiment}

Rice samples were sampled on 8 July (tillering stage), 1 September (heading stage) and 17 October (mature stage) 2015 and 27 July (tillering stage), 12 September (heading stage) and 25 October (mature stage) 2016. In 2015, every fertilization treatment had three plots, and two plants were randomly collected from each plot, then totally six samples were obtained. In 2016, every fertilization treatment had four plots, and three plants were collected and mixed as one sample in each plot. The plants were uprooted and immediately transported to the laboratory on ice. After separated from roots, the rhizosphere soil was thoroughly homogenized and sieved $(2 \mathrm{~mm})$. Then the soil was divided into two parts: part one was stored at $-80^{\circ} \mathrm{C}$ for DNA and RNA extraction; part two was air-dried and sent to the Qiyang Red Soil Experimental Station $\left(26^{\circ} 45^{\prime} \mathrm{N}, 111^{\circ} 52^{\prime} \mathrm{E}\right.$, Hunan Province, China) for soil physical and chemical analysis [78]. Soil nitrate-nitrogen $\left(\mathrm{NO}_{3}{ }^{-}\right.$ $\mathrm{N})$ and ammonium-nitrogen $\left(\mathrm{NH}_{4}-\mathrm{N}\right)$ were analyzed using a continuous flow analytical system [79]. Before DNA and RNA extraction, roots were sterilized with $75 \%$ ethanol for $1 \mathrm{~min}$ and $1 \% \mathrm{NaClO}$ for $4 \mathrm{~min}$. The last washing solution was coated in TSA solid medium to detect whether the roots were completely disinfected.

\section{DNA extraction and nifH Illumina sequencing}

Soil DNA and RNA were extracted using FastDNA ${ }^{T M}$ SPIN Kit for Soil (MP Biomedical, Irvine, CA, USA) and RNA PowerSoil@ Total RNA Isolation Kit (MO BIO Laboratories, Inc., Carlsbad, CA, USA) according to the manufacturer's instructions. Rice root DNA and RNA were extracted by PowerPlant ${ }^{\circledR}$ DNA Isolation kit (Mo Bio) and RNApure Plant Kit (PD biotech, Shanghai, China). The extracted DNA and RNA were evaluated on a $1 \%$ agarose gel. The reverse transcription was performed using PrimeScript ${ }^{\mathrm{TM}} \mathrm{RT}$ reagent Kit with gDNA Eraser (Takara, Dalian, China).

The primers nifH1 (5'-barcode-TGYGAYCCNAARGCNGA-3') and nifH2 (5'-ADNGCCATCATYTCNCC-3') were used to amplify a 359-bp sequence of nifH gene [80]. Barcode is an eight-base sequence unique to each sample. PCR reactions were performed in triplicate to minimize PCR bias which contained $4 \mu \mathrm{L}$ of $5 \times$ FastPfu Buffer, $2 \mu \mathrm{L}$ of $2.5 \mathrm{mM}$ dNTPs, $0.8 \mu \mathrm{L}$ of each primer $(5 \mu \mathrm{M}), 0.4 \mu \mathrm{L}$ of FastPfu Polymerase, and $10 \mathrm{ng}$ of template DNA or complementary DNA [81]. Purified PCR products were pooled in equimolar and paired-end sequenced $(2 \times 250 \mathrm{bp})$ on the lllumina MiSeq platform (Biozeron, Shanghai, China) according to the standard protocols.

\section{Sequence processing and statistical analyses}


Raw fastq files were quality-filtered with the following criteria: (1) Bases of each read whose quality scores $<20$ were discarded. Only the reads with perfectly matched barcodes, primers $<2$ nucleotides mismatch and containing no ambiguous character were kept. (2) Then the barcodes and primers were deleted. (3) The remaining forward and reverse reads with at least 10 -bp overlap were combined into a single sequence using FLASH. Combined sequences of less than 250-bp were discarded. The quantified reads were translated into protein sequences and corrected potential frameshifts using FrameBot program ( http://fungene.cme.msu.edu/FunGenePipeline/) and the corresponding FunGene database (http://fungene.cme.msu.edu/) (min length=100 amino acids, $\mathrm{hmm}=50 \%$ ) as a reference [43,82-83]. Reads having inframe stop codon (s) were manually removed. Then the protein reads were removed singleton, dereplicated and clustered into OTUs using the UPARSE pipeline at $90 \%$ identity [84-86]. Chimeric sequences were then identified and removed using UPARSE in de novo mode. Finally, OTUs that contained one sequence were removed. To assign putative taxonomy, representative sequences were aligned to a closest-match sequence of the FunGene database by BLASTp [87-88].

Chao1, Shannon and PD indices were calculated by Mothur software after sequences were normalized. Rarefaction curves, bar plots, cluster trees, heatmaps and bubble plots were drawn using R (Version 3.4.0). The Mental tests, PERMANOVA and ANOSIM analysis were conducted using the mental(), adonis() and anosim() functions from the Vegan package in $\mathrm{R}$, respectively. NMDS was conducted on the Bray-Curtis distance matrix using the vegan $\mathrm{R}$ package. Spearman correlation analysis between diazotrophic taxa and soil physicochemical indices was performed using the corrplot library in R. To identify the phylogenetic affiliation of nifH sequences, neighbor-joining ( $\mathrm{NJ}$ ) trees were constructed using the molecular evolutionary genetics analysis (MEGA) software for the 50 most abundant OTUs together with selected reference sequences. To track the dynamics of individual OTUs among different samples, Sankey plots were constructed based on D3.js (v.5.14.2) (d3js.org) [89]. Bacterial taxonomic flow at the class level was drawn based on the OTU table of all samples, and for OTUs shared by soil and root samples, the OTU table was further filtered to OTUs whose abundance is less than $0.05 \%$. The extended error bar plots were carried by STAMP software (Statistical Analysis of Metagenomic Profiles; https://beikolab.cs.dal.ca/software/STAMP) to filter fertilization-sensitive and root-enriched biomarkers. The online LEfSe program (http://huttenhower.sph.harvard.edu/galaxy/root?tool_id=PICRUSt_normalize) was performed to find biomarker whose relative abundance significantly changed during rice growth. The co-occurrence network was constructed with the 'psych' package by using the Spearman correlation, and the correlations with a Spearman coefficient of less than 0.65 and an adjusted $P$ values of more than 0.01 , were removed. The network images were generated and the network properties were calculated with Gephi (https://gephi.org/). The other statistical analyses were conducted using SPSS 19.0. (SPSS Inc., USA).

\section{Abbreviations}

BNF: biological nitrogen fixation; NUE: nitrogen-use efficiency; ARA: acetylene reduction activity; NCR: nodule-specific cysteine-rich; OTUs: operational taxonomic units; OM: organic matter; TN: total N; TP: total P; TK: total K; AN: available N; AP: available P; AK: available K; NO3-N: nitrate-nitrogen; NH4-N: ammonium-nitrogen; PGPB: plant growth-promoting bacteria.

\section{Declarations}

\section{Acknowledgements}

We thank Associate Prof. Jiaqin Fan of Nanjing Agricultural University for generously providing greenhouse, Prof. Yongfeng Li of Jiangsu Academy of Agricultural Sciences, Nanjing, China, for kind providing assistance in rice cultivation management.

\section{Funding}


This work was supported by the Genetically Modified Organisms Breeding Major Projects of China (2016ZX08011-003), the Natural Science Foundation of China (32000101), China Postdoctoral Science Foundation (2020M671513),

Fundamental Research Funds for Central Non-profit Scientific Institution (1610132017041), and the Major State Basic Research Development Program of China (973 program, No. 2015CB150502).

\section{Author information}

\section{Author notes}

Xue Luo and Xianfeng Ye contributed equally to this work.

\section{Contributions}

$\mathrm{ZC}, \mathrm{HC}$ and WR conceived the study. $\mathrm{XL}$ and $\mathrm{WW}$ performed data analyses. $\mathrm{XL}, \mathrm{XY}, \mathrm{WW}, \mathrm{ZL}$, and $\mathrm{YQ}$ collected samples and performed the DNA and RNA extractions. $Y C, C D$, and $Y Z$ performed parts of the experiment. $X L, X Y, W W$, and $Z C$ edited the manuscript. $\mathrm{YH}, \mathrm{MH}, \mathrm{XF}$ and $\mathrm{HJ}$ revised the manuscript. All authors read and approved the final manuscript.

\section{Availability of data and materials}

The datasets generated and analyzed during the current study are available in the NCBI Sequence Read Archive (SRA) repository under the BioProject with accession codes PRJNA666552

(https://www.ncbi.nlm.nih.gov/bioproject/PRJNA666552).

\section{Ethics approval and consent to participate}

Not applicable.

\section{Consent for publication}

Not applicable.

\section{Competing interests}

The authors declare that there are no competing interests.

\section{References}

1. Novoa R, Loomis RS. Nitrogen and plant production. Plant Soil. 1981;58:177-204.

2. Zhang X, Davidson EA, Mauzerall DL, Searchinger TD, Dumas P, Shen Y. Managing nitrogen for sustainable development. Nature. 2015;528:51-59.

3. Vitousek PM, Aber JD, Howarth RW, Likens GE, Matson PA, Schindler DW, et al. Technical report: human alteration of the global nitrogen cycle: sources and consequences. Ecol Appl. 1997;7(3):737-50.

4. Islam R, Trivedi P, Madhaiyan M, Seshadri S, Lee G, Yang J, et al. Isolation, enumeration, and characterization of diazotrophic bacteria from paddy soil sample under long-term fertilizer management experiment. Biol Fertil Soils. 2010;46:261-69.

5. Park M, Kim C, Yang J, Lee H, Shin W, Kim S, et al. Isolation and characterization of diazotrophic growth promoting bacteria from rhizosphere of agricultural crops of Korea. Microbiol Res. 2005;160:127-33.

6. Liu H, Zhang L, Meng A, Zhang J, Xie M, Qin Y, et al. Isolation and molecular identification of endophytic diazotrophs from seeds and stems of three cereal crops. PLoS One. 2017;12(10):e0187383. 
7. Balachandar D, Sandhiya GS, Sugitha TCK, Kumar K. Flavonoids and growth hormones influence endophytic colonization and in planta nitrogen fixation by a diazotrophic Serratia sp. in Rice. World J Microb Biot. 2006;22:70712.

8. Baldani VLD, Baldani JI, Döbereiner J. Inoculation of rice plants with the endophytic diazotrophs Herbaspirillum seropedicae and Burkholderia spp. Biol Fertil Soils. 2000;30:485-91.

9. Weselowski B, Nathoo N, Eastman AW, MacDonald J, Yuan ZC. Isolation, identification and characterization of Paenibacillus polymyxa CR1 with potentials for biopesticide, biofertilization, biomass degradation and biofuel production. BMC Microbiol. 2016;16:244.

10. Naveed M, Mitter B, Reichenauer TG, Wieczorek K, Sessitsch A. Increased drought stress resilience of maize through endophytic colonization by Burkholderia phytofirmans PsJN and Enterobactersp. FD17. Environ Exp Bot. 2014;97:3039.

11. Liang Y, Pan F, He X, Chen X, Su Y. Effect of vegetation types on soil arbuscular mycorrhizal fungi and nitrogen-fixing bacterial communities in a karst region. Environ Sci Pollut Res. 2016;23:18482-91.

12. Zhang Y, Yang Q, Ling J, Van Nostrand JD, Shi Z, Zhou J, et al. Diversity and structure of diazotrophic communities in mangrove rhizosphere, revealed by high-throughput sequencing. Front Microbiol. 2017;8:2023.

13. Rodríguez-Blanco A, Sicardi M, Frioni L. Plant genotype and nitrogen fertilization effects on abundance and diversity of diazotrophic bacteria associated with maize (Zea mays L.). Biol Fertil Soils. 2015;51:391-402.

14. Lin Y, Ye G, Liu DY Ledgard S, Luo J, Fan J, et al. Long-term application of lime or pig manure rather than plant residues suppressed diazotroph abundance and diversity and altered community structure in an acidic Ultisol. Soil Biol Biochem. 2018;123:218-28.

15. Wang C, Zheng M, Song W, Wen S, Wang B, Zhu C, et al. Impact of 25 years of inorganic fertilization on diazotrophic abundance and community structure in an acidic soil in southern China. Soil Biol Biochem. 2017;113:240-49.

16. Hu X, Liu J, Wei D, Zhou B, Chen X, Jin J, et al. Long-term application of nitrogen, not phosphate or potassium, significantly alters the diazotrophic community compositions and structures in a Mollisol in northeast China. Res Microbiol. 2019;170:147-55.

17. Bulgarelli D, Schlaeppi K, Spaepen S, van Themaat EVL, Schulze-Lefert P. Structure and functions of the bacterial microbiota of plants. Annu Rev Plant Biol. 2013;64:807-38.

18. Zhalnina K, Louie KB, Hao Z, Mansoori N, da Rocha UN, Shi S, et al. Dynamic root exudate chemistry and microbial substrate preferences drive patterns in rhizosphere microbial community assembly. Nat Microbiol. 2018;3:470-80.

19. Zhang R, Vivanco JM, Shen Q. The unseen rhizosphere root-soil-microbe interactions for crop production. Curr Opin Microbiol. 2017;37:8-14.

20. Van de Velde W, Zehirov G, Szatmari A, Debreczeny M, Ishihara H, Kevei Z, et al. Plant peptides govern terminal differentiation of bacteria in symbiosis. Science. 2010;327:1122-26.

21. Zhang J, Zhang N, Liu Y, Zhang X, Hu B, Qin Y, et al. Root microbiota shift in rice correlates with resident time in the field and developmental stage. Sci China Life Sci. 2018;61(6):613-21.

22. Edwards JA, Santos-Medellín CM, Liechty ZS, Nguyen B, Lurie E, Eason S, et al. Compositional shifts in rootassociated bacterial and archaeal microbiota track the plant life cycle in field-grown rice. PLoS Biol. 2018;16(2):e2003862.

23. Zehr JP, Jenkins BD, Short SM, Steward GF. Nitrogenase gene diversity and microbial community structure: a crosssystem comparison. Environ Microbiol. 2003;5(7):539-54.

24. Malik KA, Bilal R, Mehnaz S, Rasul G, Mirza MS, Ali S. Association of nitrogen-fixing, plant-growth-promoting rhizobacteria (PGPR) with kallar grass and rice. Plant Soil. 1997;194:37-44. 
25. Garau G, Yates RJ, Deiana P, Howieson JG. Novel strains of nodulating Burkholderia have a role in nitrogen fixation with papilionoid herbaceous legumes adapted to acid, infertile soils. Soil Biol Biochem. 2009;41:125-34.

26. Ladha JK, Tirol-Padre A, Reddy CK, Cassman KG, Verma S, Powlson DS, et al. Global nitrogen budgets in cereals: A 50-year assessment for maize, rice, and wheat production systems. Sci Rep. 2016;6:19355.

27. Segata N, Izard J, Waldron L, Gevers D, Miropolsky L, Garrett WS, et al. Metagenomic biomarker discovery and explanation. Genome biol. 2011;12:R60.

28. Ata-Ul-Karim ST, Zhu Y, Yao X, Cao W. Determination of critical nitrogen dilution curve based on leaf area index in rice. Field Crops Res. 2014;167:76-85.

29. Tang Y, Zhang M, Chen A, Zhang W, Wei W, Sheng R. Impact of fertilization regimes on diazotroph community compositions and N2-fixation activity in paddy soil. Agr Ecosyst Environ. 2017;247:1-8.

30. Wartiainen I, Eriksson T, Zheng W, Rasmussen U. Variation in the active diazotrophic community in rice paddy-nifH PCR-DGGE analysis of rhizosphere and bulk soil. Appl Soil Ecol. 2008;39(1):65-75.

31. Tan Z, Hurek T, Reinhold-Hurek B. Effect of N-fertilization, plant genotype and environmental conditions on nifH gene pools in roots of rice. Environ Microbiol. 2003;5(10):1009-15.

32. Wang J, Zhang D, Zhang L, Li J, Raza W, Huang Q, et al. Temporal variation of diazotrophic community abundance and structure in surface and subsoil under four fertilization regimes during a wheat growing season. Agr Ecosyst Environ. 2016;216:116-24.

33. Chakraborty A, Islam E. Temporal dynamics of total and free-living nitrogen-fixing bacterial community abundance and structure in soil with and without history of arsenic contamination during a rice growing season. Environ Sci Pollut Res. 2018;25:4951-62.

34. Bacilio-Jiménez M, Aguilar-Flores S, Ventura-Zapata E, Pérez-Campos E, Bouquelet S, Zenteno E. Chemical characterization of root exudates from rice (Oryza sativa) and their effects on the chemotactic response of endophytic bacteria. Plant Soil. 2003;249:271-77.

35. Rosenblueth M, Martínez-Romero E. Bacterial endophytes and their interactions with hosts. Mol Plant Microbe Interact. 2006;19(8):827-37.

36. Roesch LFW, Camargo FAO, Bento FM, Triplett EW. Biodiversity of diazotrophic bacteria within the soil, root and stem of field-grown maize. Plant Soil. 2008;302:91-104.

37. Gottel NR, Castro HF, Kerley M, Yang Z, Pelletier DA, Podar M, et al. Distinct microbial communities within the endosphere and rhizosphere of Populus deltoides roots across contrasting soil types. Appl Environ Microbiol. 2011;77(17):5934-44.

38. Zheng Y, Gong X. Niche differentiation rather than biogeography shapes the diversity and composition of microbiome of Cycas panzhihuaensis. Microbiome. 2019;7:152.

39. Beckers B, Op De Beeck M, Weyens N, Boerjan W, Vangronsveld J. Structural variability and niche differentiation in the rhizosphere and endosphere bacterial microbiome of field-grown poplar trees. Microbiome. 2017;5:25.

40. Liu X, Yang C, Yu X, Yu H, Zhuang W, Gu H, et al. Revealing structure and assembly for rhizophyte-endophyte diazotrophic community in mangrove ecosystem after introduced Sonneratia apetala and Laguncularia racemosa. Sci Total Environ. 2020;721:137807.

41. Liao H, Li Y, Yao H. Fertilization with inorganic and organic nutrients changes diazotroph community composition and N-fixation rates. J Soils Sediments. 2018;18:1076-86.

42. Wu L, Ma K, Lu Y. Prevalence of Betaproteobacterial sequences in nifH gene pools associated with roots of modern rice cultivars. Microb Ecol. 2009;57:58-68.

43. Wang Q, Quensen JF, Fish JA, Lee TK, Sun Y, Tiedje JM, et al. Ecological patterns of nifH genes in four terrestrial climatic zones explored with targeted metagenomics using FrameBot, a new informatics tool. mBio. 
2013;4(5):e00592-13.

44. Ferrando Lucía, Scavino AF. Strong shift in the diazotrophic endophytic bacterial community inhabiting rice (Oryza sativa) plants after flooding. FEMS Microbiol Ecol. 2015;91(9):fiv104.

45. Rilling JI, Acuna JJ, Sadowsky MJ, Jorquera MA. Putative nitrogen-fixing bacteria associated with the rhizosphere and root endosphere of wheat plants grown in an andisol from southern Chile. Front Microbiol. 2018;9:2710.

46. Orr CH, Leifert C, Cummings SP, Cooper JM. Impacts of organic and conventional crop management on diversity and activity of free-living nitrogen fixing bacteria and total bacteria are subsidiary to temporal effects. PLoS One. 2012;7(12):e52891.

47. Estrada P, Mavingui P, Cournoyer B, Fontaine F, Balandreau J, Caballero-Mellado J. A $\mathrm{N}_{2}$-fixing endophytic Burkholderia sp. associated with maize plants cultivated in Mexico. Can J Microbiol. 2002;48:285-94.

48. Ho Y, Chiang H, Chao C, Su C, Hsu H, Guo C, et al. In planta biocontrol of soilborne Fusarium wilt of banana through a plant endophytic bacterium, Burkholderia cenocepacia 869T2. Plant Soil. 2015;387:295-306.

49. Gutiérrez-Zamora ML, Martínez-Romero E. Natural endophytic association between Rhizobium etli and maize (Zea mays L.). J Biotechnol. 2001;91:117-26.

50. Biswas JC, Ladha JK, Dazzo FB. Rhizobia inoculation improves nutrient uptake and growth of lowland rice. Soil Sci Soc Am J. 2000;64:1644-50.

51. Estrada GA, Baldani VLD, de Oliveira DM, Urquiaga S, Baldani JI. Selection of phosphate-solubilizing diazotrophic Herbaspirillum and Burkholderia strains and their effect on rice crop yield and nutrient uptake. Plant Soil. 2013;369:115-29.

52. Govindarajan M, Balandreau J, Kwon SW, Weon HY, Lakshminarasimhan C. Effects of the inoculation of Burkholderia vietnamensis and related endophytic diazotrophic bacteria on grain yield of rice. Microb Ecol. 2008;55:21-37.

53. Ju X, Zhao L, Sun B. Nitrogen fixation by reductively dechlorinating bacteria. Environ Microbiol. 2007;9(4):1078-83.

54. Bryantseva I, Gorlenko VM, Kompantseva El, Imhoff JF, Suling J, Mityushina L. Thiorhodospira sibirica gen. nov., sp. nov., a new alkaliphilic purple sulfur bacterium from a Siberian soda lake. Int J Syst Bacteriol. 1999;49:697-703.

55. Prakamhang J, Minamisawa K, Teamtaisong K, Boonkerd N, Teaumroong N. The communities of endophytic diazotrophic bacteria in cultivated rice (Oryza sativa L.). Appl Soil Ecol. 2009;42:141-49.

56. Severin I, Stal LJ. Spatial and temporal variability in nitrogenase activity and diazotrophic community composition in coastal microbial mats. Mar Ecol Prog Ser. 2010;417:13-25.

57. Pereira e Silve MC, Semenov AV, van Elsas JD, Salles JF. Seasonal variations in the diversity and abundance of diazotrophic communities across soils. FEMS Microbiol Ecol. 2011;77:57-68.

58. Aulakh MS, Wassmann R, Bueno C, Kreuzwieser J, Rennenberg H. Characterization of root exudates at different growth stages of ten rice (Oryza sativa L.) cultivars. Plant Biol. 2001;3:139-48.

59. Ruiz Herrera LF, Shane MW, López-Bucio J. Nutritional regulation of root development. WIREs Dev Biol. 2015;4:43143.

60. Xin W, Zhang L, Zhang W, Gao J, Yi J, Zhen X, et al. An integrated analysis of the rice transcriptome and metabolome reveals root growth regulation mechanisms in response to nitrogen availability. Int J Mol Sci. 2019;20:5893.

61. de Oliveira ALM, de Lima Canuto E, Reis VM, Baldani JI. Response of micropropagated sugarcane varieties to inoculation with endophytic diazotrophic bacteria. Braz J Microbiol. 2003;34:59-61.

62. Carvalho TLG, Balsemão-Pires E, Saraiva RM, Ferreira PCG, Hemerly AS. Nitrogen signalling in plant interactions with associative and endophytic diazotrophic bacteria. J Exp Bot. 2014;65(19):5631-42.

63. Wakelin SA, Colloff MJ, Harvey PR, Marschner P, Gregg AL, Rogers SL. The effects of stubble retention and nitrogen application on soil microbial community structure and functional gene abundance under irrigated maize. FEMS microbiol Ecol. 2007;59:661-70.

Page $17 / 40$ 
64. Ogilvie LA, Hirsch PR, Johnston AWB. Bacterial diversity of the broadbalk 'classical' winter wheat experiment in relation to long-term fertilizer inputs. Microb Ecol. 2008;56:525-37.

65. Ma Q, Wu L, Wang J, Ma J, Zheng N, Hill PW, et al. Fertilizer regime changes the competitive uptake of organic nitrogen by wheat and soil microorganisms: An in-situ uptake test using ${ }^{13} \mathrm{C},{ }^{15} \mathrm{~N}$ labelling, and ${ }^{13} \mathrm{C}-\mathrm{PLFA}$ analysis. Soil Biol Biochem. 2018;125:319-27.

66. Knauth S, Hurek T, Brar D, Reinhold-Hurek B. Influence of different Oryza cultivars on expression of nifH gene pools in roots of rice. Environ Microbiol. 2005;7(11):1725-33.

67. Gonzalez Perez P, Ye J, Wang S, Wang X, Huang D. Analysis of the occurrence and activity of diazotrophic communities in organic and conventional horticultural soils. Appl Soil Ecol. 2014;79:37-48.

68. Welsh AK, Burke DJ, Hamerlynck EP, Hahn D. Seasonal analyses of arbuscular mycorrhizae, nitrogen-fixing bacteria and growth performance of the salt marsh grass Spartina patens. Plant Soil. 2010;330:251-66.

69. Zhang Q, Acuña JJ, Inostroza NG, Duran P, Mora ML, Sadowsky MJ, et al. Niche differentiation in the composition, predicted function, and co-occurrence networks in bacterial communities associated With antarctic vascular plants. Front Microbiol. 2020;11:1036.

70. Yao H, Sun X, He C, Maitra P, Li X, Guo L. Phyllosphere epiphytic and endophytic fungal community and network structures differ in a tropical mangrove ecosystem. Microbiome. 2019;7(1):57.

71. Bulgarelli D, Rott M, Schlaeppi K, van Themaat EVL, Ahmadinejad N, Assenza F, et al. Revealing structure and assembly cues for Arabidopsis root-inhabiting bacterial microbiota. Nature. 2012;488:91-95.

72. Poly F, Monrozier LJ, Bally R. Improvement in the RFLP procedure for studying the diversity of nifH genes in communities of nitrogen fixers in soil. Res Microbiol. 2001;152:95-103.

73. Yoshida S, Forno DA, Cock JH, Gomez KA. Laboratory manual for physiological studies of rice. Int. Rice Res. Inst. 1976:60-5.

74. Lv X, Weng X, Zhang W, Rao P, Ni L. Microbial diversity of traditional fermentation starters for Hong Qu glutinous rice wine as determined by PCR-mediated DGGE. Food Control. 2012;28:426-34.

75. Haahtela K, Wartiovaara T, Sundman V, Skujins J. Root-associated N2 fixation (acetylene reduction) by Enterobacteriaceae and Azospirillum strains in cold-climate spodosols. Appl Environ Microbiol. 1981;41(1):203-06.

76. Glickmann E, Dessaux Y. A critical examination of the specificity of the salkowski reagent for indolic compounds produced by phytopathogenic bacteria. Appl Environ Microbiol. 1995;61(2):793-96.

77. Schwyn B, Neilands JB. Universal chemical assay for the detection and determination of siderophores. Anal Biochem. 1987;160:47-56.

78. Wang W, Wang H, Feng Y, Wang L, Xiao X, Xi Y, et al. Consistent responses of the microbial community structure to organic farming along the middle and lower reaches of the Yangtze River. Sci Rep. 2016;6:35046.

79. Sun R, Zhang X, Guo X, Wang D, Chu H. Bacterial diversity in soils subjected to long-term chemical fertilization can be more stably maintained with the addition of livestock manure than wheat straw. Soil Biol Biochem. 2015;88:9-18.

80. Zehr JP, Mcreynolds LA. Use of degenerate oligonucleotides for amplification of the nifH gene from the marine Cyanobacterium Trichodesmium thiebautii. Appl Environ Microbiol. 1989;55(10):2522-26.

81. Hong C, Si Y, Xing Y, Li Y. Illumina MiSeq sequencing investigation on the contrasting soil bacterial community structures in different iron mining areas. Environ Sci Pollut Res. 2015;22:10788-99.

82. Penton CR, Louis DS, Pham A, Cole JR, Wu L, Luo Y, et al. Denitrifying and diazotrophic community responses to artificial warming in permafrost and tallgrass prairie soils. Front Microbiol. 2015;6:746.

83. Fish JA, Chai B, Wang Q, Sun Y, Brown CT, Tiedje JM, et al. FunGene: the functional gene pipeline and repository. Front Microbiol. 2013;4:291. 
84. Edgar RC. UPARSE: highly accurate OTU sequences from microbial amplicon reads. Nat Methods. 2013;10(10):99698.

85. Lema KA, Willis BL, Bourne DG. Corals form characteristic associations with symbiotic nitrogen-fixing bacteria. Appl Environ Microbiol. 2012;78(9):3136-44.

86. Lema KA, Willis BL, Bourne DG. Amplicon pyrosequencing reveals spatial and temporal consistency in diazotroph assemblages of the Acropora millepora microbiome. Environ Microbiol. 2014;16(10):3345-59.

87. Zhang B, Penton CR, Xue C, Wang Q, Zheng T, Tiedje JM. Evaluation of the lon Torrent Personal Genome Machine for gene-targeted studies using amplicons of the nitrogenase gene, nifH. Appl Environ Microbiol. 2015;81(13):4536-45.

88. Messer LF, Mahaffey C, Robinson CM, Jeffries TC, Baker KG, Isaksson JB, et al. High levels of heterogeneity in diazotroph diversity and activity within a putative hotspot for marine nitrogen fixation. ISME J. 2016;10:1499-513.

89. Ren Y, Xun W, Yan H, Ma A, Xiong W, Shen Q, et al. Functional compensation dominates the assembly of plant rhizospheric bacterial community. Soil Biol Biochem. 2020;150:107968.

\section{Tables}

Table 1 Effect of inoculation of root grinding fluid on rice root, plant height and biomass under different $\mathrm{N}$ concentrations in the hydroponic experiment.

\begin{tabular}{|llll|}
\hline & $\mathrm{C}_{20}$ & $\mathrm{~T}_{20}$ & $\mathrm{~T}_{10}$ \\
\hline fresh weight/g & $2.25 \pm 0.41 \mathrm{~b}$ & $2.36 \pm 0.46 \mathrm{~b}$ & $3.26 \pm 0.54 \mathrm{a}$ \\
\hline root length/cm & $13.46 \pm 1.19 \mathrm{~b}$ & $13.53 \pm 0.91 \mathrm{~b}$ & $19.51 \pm 2.03 \mathrm{a}$ \\
\hline plant height/cm & $37.04 \pm 1.68 \mathrm{~b}$ & $36.35 \pm 1.85 \mathrm{~b}$ & $39.08 \pm 1.47 \mathrm{a}$ \\
\hline $\mathrm{N}$ concentration/\% & $2.84 \pm 0.06 \mathrm{a}$ & $2.77 \pm 0.04 \mathrm{a}$ & $2.83 \pm 0.3 \mathrm{a}$ \\
\hline$\delta^{15} \mathrm{~N} /$ atom\% & $33.26 \pm 1.1 \mathrm{a}$ & $33.85 \pm 0.25 \mathrm{a}$ & $29.43 \pm 0.49 \mathrm{~b}$ \\
\hline
\end{tabular}

Note: $T_{20}$ and $T_{10}$ were inoculated with rice root grinding fluid, and $\mathrm{C}_{20}$ was uninoculated. $\mathrm{C}_{20}, \mathrm{~T}_{20}$ and $\mathrm{T}_{10}$ were cultured at 20, 20 and $10 \mathrm{ppm}{ }^{15} \mathrm{~N}$-labeled $\left(\mathrm{NH}_{4}\right)_{2} \mathrm{SO}_{4}$ (50 atom\% excess), respectively. Twelve seedlings were cultured per treatment, and four seedlings were taken as a sample when measuring $\mathrm{N}$ concentration and $\delta^{15} \mathrm{~N}$. Different lowercase letters indicate significant differences between treatments $(P<0.05$, Tukey's honestly significant difference (HSD) test).

Table 2 Effects of experimental variables on total rhizosphere and endophytic diazotrophic a-diversity and $\beta$-diversity. 


\begin{tabular}{|c|c|c|c|c|c|c|c|c|}
\hline & \multicolumn{4}{|c|}{ Total rhizosphere diazotrophs } & \multicolumn{4}{|c|}{ Total endophytic diazotrophs } \\
\hline & $\begin{array}{l}\beta \\
\text { diversity }\end{array}$ & $\begin{array}{l}\text { Richness } \\
\text { (Chao1) }\end{array}$ & $\begin{array}{l}\text { Evenness } \\
\text { (Shannon) }\end{array}$ & PD & $\begin{array}{l}\beta \\
\text { diversity }\end{array}$ & $\begin{array}{l}\text { Richness } \\
\text { (Chao1) }\end{array}$ & $\begin{array}{l}\text { Evenness } \\
\text { (Shannon) }\end{array}$ & PD \\
\hline year & $0.19 * * *$ & 0 & $0.22 * \star \star$ & 0 & $0.06 * * *$ & $0.05 * \star \star$ & $0.05^{\star * *}$ & $0.03^{* *}$ \\
\hline period & $0.22 * \star *$ & $0.08 *$ & $0.18 * * *$ & $0.26 * * *$ & $0.33^{* * *}$ & $0.51 * \star *$ & $0.51 * * *$ & $0.53^{* \star \star}$ \\
\hline fertilizer & 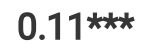 & 0.05 & $0.06 * \star$ & 0.02 & $0.05^{\star \star \star}$ & 0.02 & $0.04 * \star$ & 0.01 \\
\hline year:period & $0.11 * * *$ & 0.04 & $0.05^{\star *}$ & 0.01 & $0.08 * \star *$ & $0.04^{\star \star}$ & $0.09 * \star *$ & $0.04^{* * *}$ \\
\hline year:fertilizer & $0.02^{\star *}$ & 0.02 & 0 & 0.01 & $0.02 *$ & 0 & 0.01 & 0.02 \\
\hline period:fertilizer & $0.04^{\star \star}$ & 0.05 & 0.04 & 0.03 & $0.09 * * *$ & 0.02 & $0.05^{\star *}$ & $0.05^{*}$ \\
\hline year:period:fertilizer & 0.03 & 0.03 & 0.03 & 0.07 & $0.04^{* * *}$ & 0.01 & $0.03 *$ & 0.03 \\
\hline
\end{tabular}

Note: The effects of experimental factors and their interactions were assessed by a non-parametric PERMANOVA analysis. Significance level: $P<0.05, * ; P<0.01, \star * ; P<0.001, \star \star \star$. The PERMANOVA analysis of $\beta$-diversity was performed at the OTU level.

\section{Figures}


a

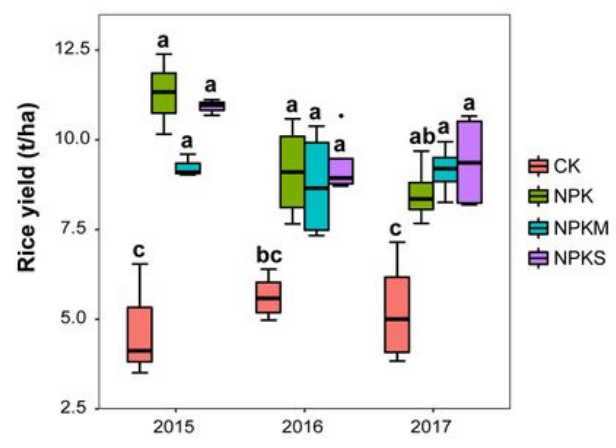

C

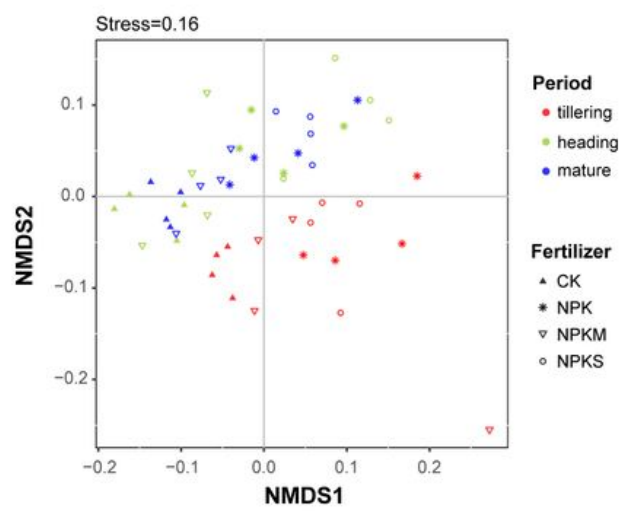

b

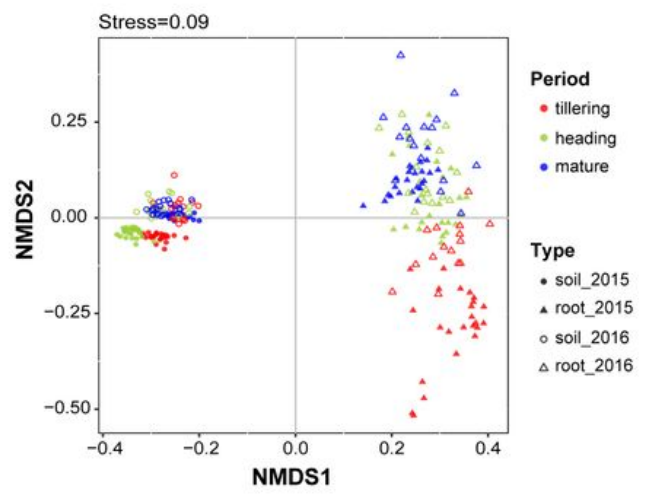

d

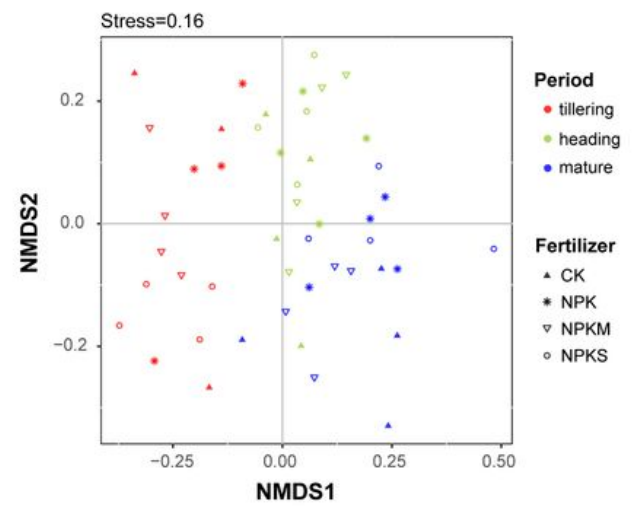

e

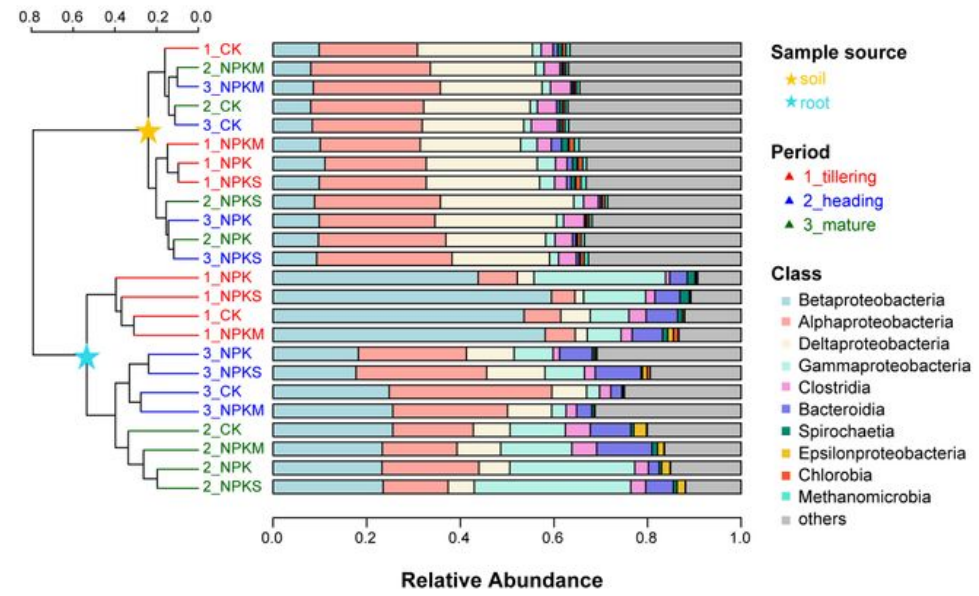

Figure 1

Rice yields in different fertilization treatments (a). NMDS analysis of total diazotrophic community structure of all DNA samples in 2015 and 2016 (b). NMDS analyses of total diazotrophic community structure in rhizosphere soil (c) and rice roots (d) in 2016. Diazotrophic community composition of the rhizosphere soil and rice roots DNA samples in 2016 at the class level (e). Note: Different lowercase letters indicate significant differences between different fertilization treatments $(P<0.05$, Tukey's HSD test). NMDS analysis and cluster tree were based on Bray-Curtis similarities at the OTU level. 
a

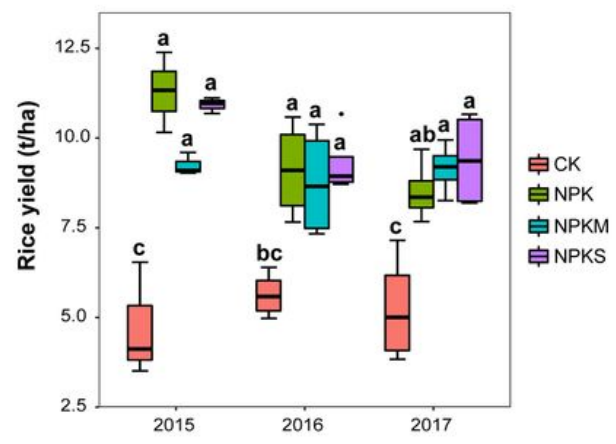

C

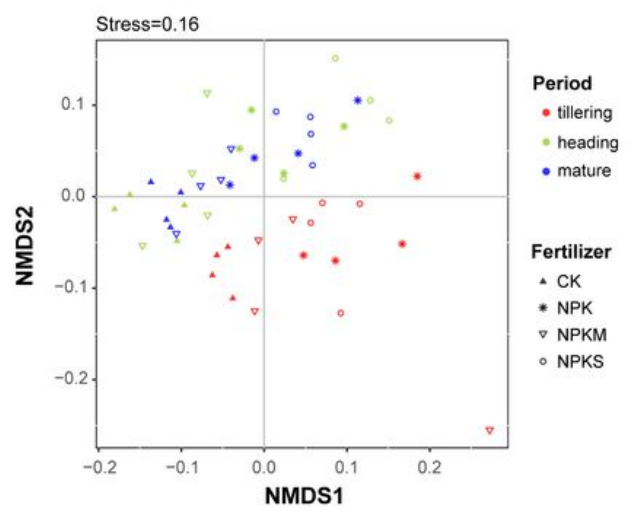

b

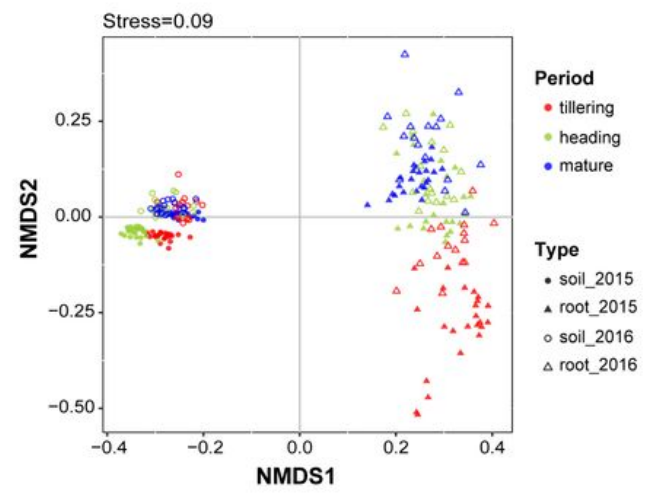

d

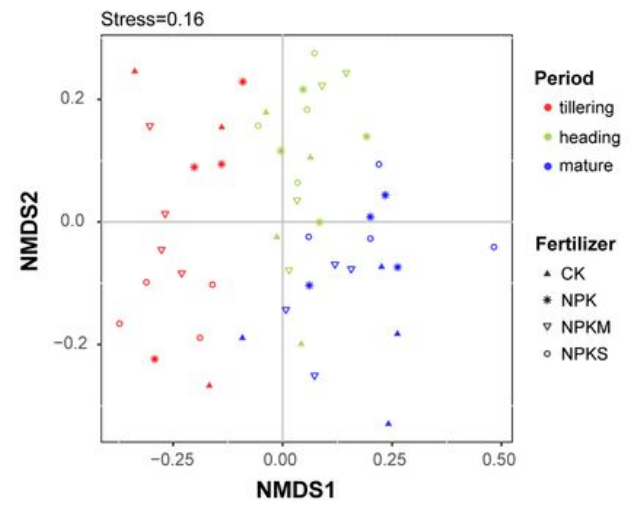

e

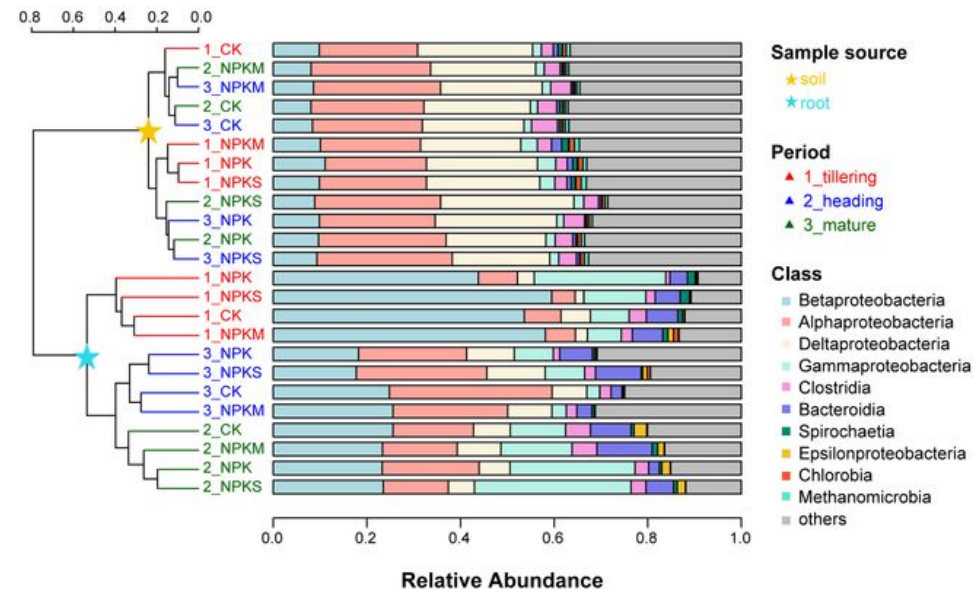

Figure 1

Rice yields in different fertilization treatments (a). NMDS analysis of total diazotrophic community structure of all DNA samples in 2015 and 2016 (b). NMDS analyses of total diazotrophic community structure in rhizosphere soil (c) and rice roots (d) in 2016. Diazotrophic community composition of the rhizosphere soil and rice roots DNA samples in 2016 at the class level (e). Note: Different lowercase letters indicate significant differences between different fertilization treatments $(P<0.05$, Tukey's HSD test). NMDS analysis and cluster tree were based on Bray-Curtis similarities at the OTU level. 
a

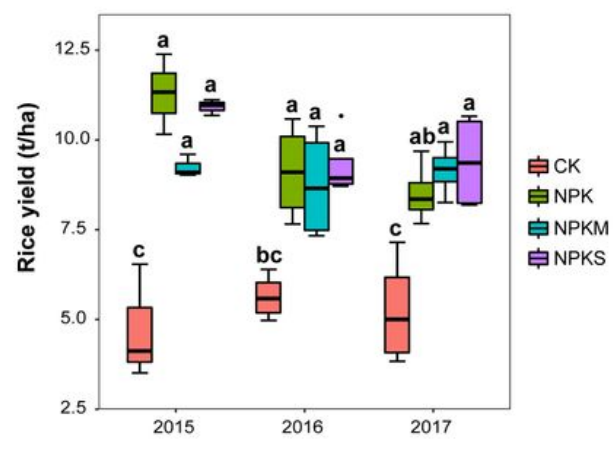

C

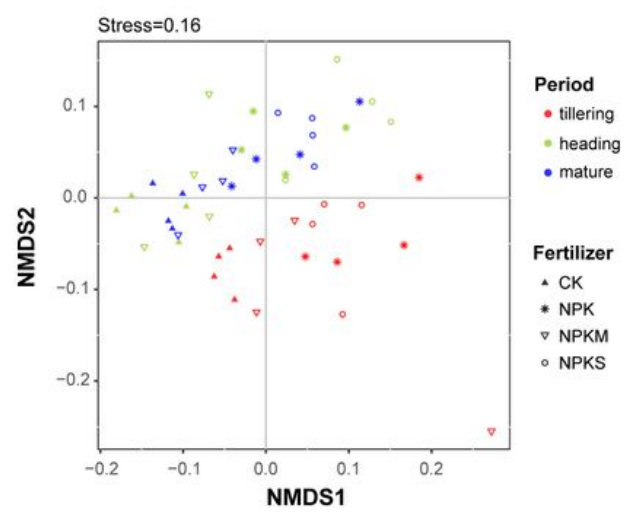

b

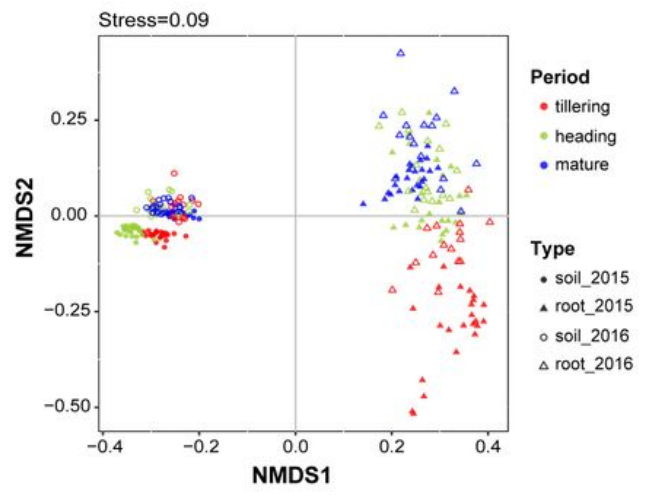

d

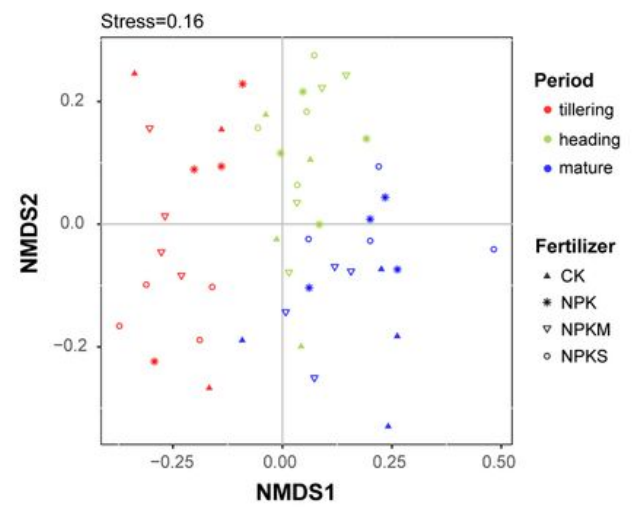

e

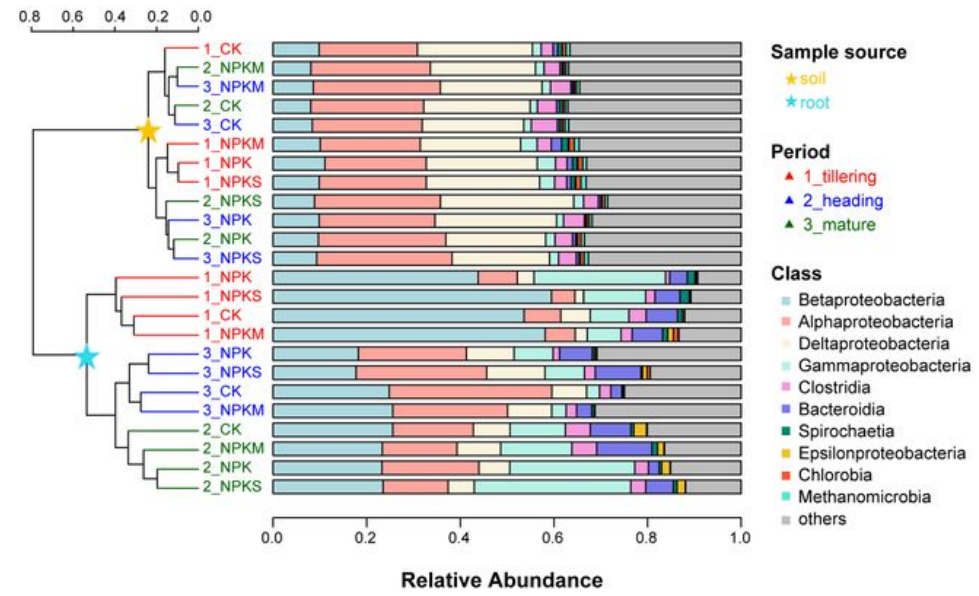

Figure 1

Rice yields in different fertilization treatments (a). NMDS analysis of total diazotrophic community structure of all DNA samples in 2015 and 2016 (b). NMDS analyses of total diazotrophic community structure in rhizosphere soil (c) and rice roots (d) in 2016. Diazotrophic community composition of the rhizosphere soil and rice roots DNA samples in 2016 at the class level (e). Note: Different lowercase letters indicate significant differences between different fertilization treatments $(P<0.05$, Tukey's HSD test). NMDS analysis and cluster tree were based on Bray-Curtis similarities at the OTU level. 


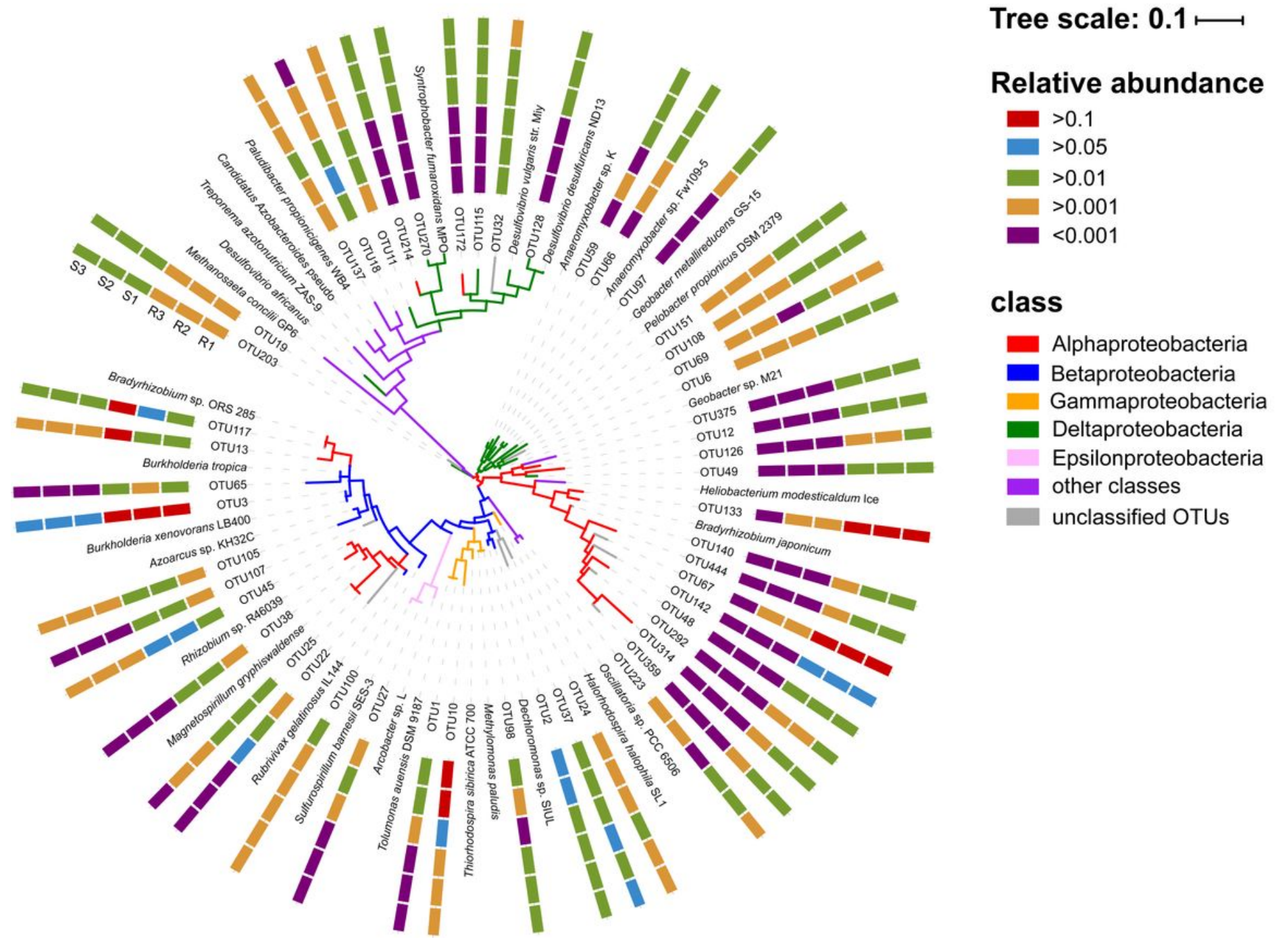

Figure 2

Neighbor-joining tree of the 50 dominant OTUs of all DNA samples in 2016 with their aligned nifH sequences from the FunGene database (bootstrap replications $=1000$ ). Note: The inner phylogenetic tree depicts the evolutionary relationship of the 50 dominant OTUs, and the outer little rectangles represent the variances of the relative abundances of these dominant OTUs during rice growth. Different colors of the inner lines represent the classes of the OTUs and their aligned nifH sequences. The color of each outer little rectangle represents the percentage of each sample in respect of the total. S1: soil DNA samples at the tillering stage; S2: soil DNA samples at the heading stage; S3: soil DNA samples at the mature stage; R1: root DNA samples at the tillering stage; R2: root DNA samples at the heading stage; R3: root DNA samples at the mature stage. 


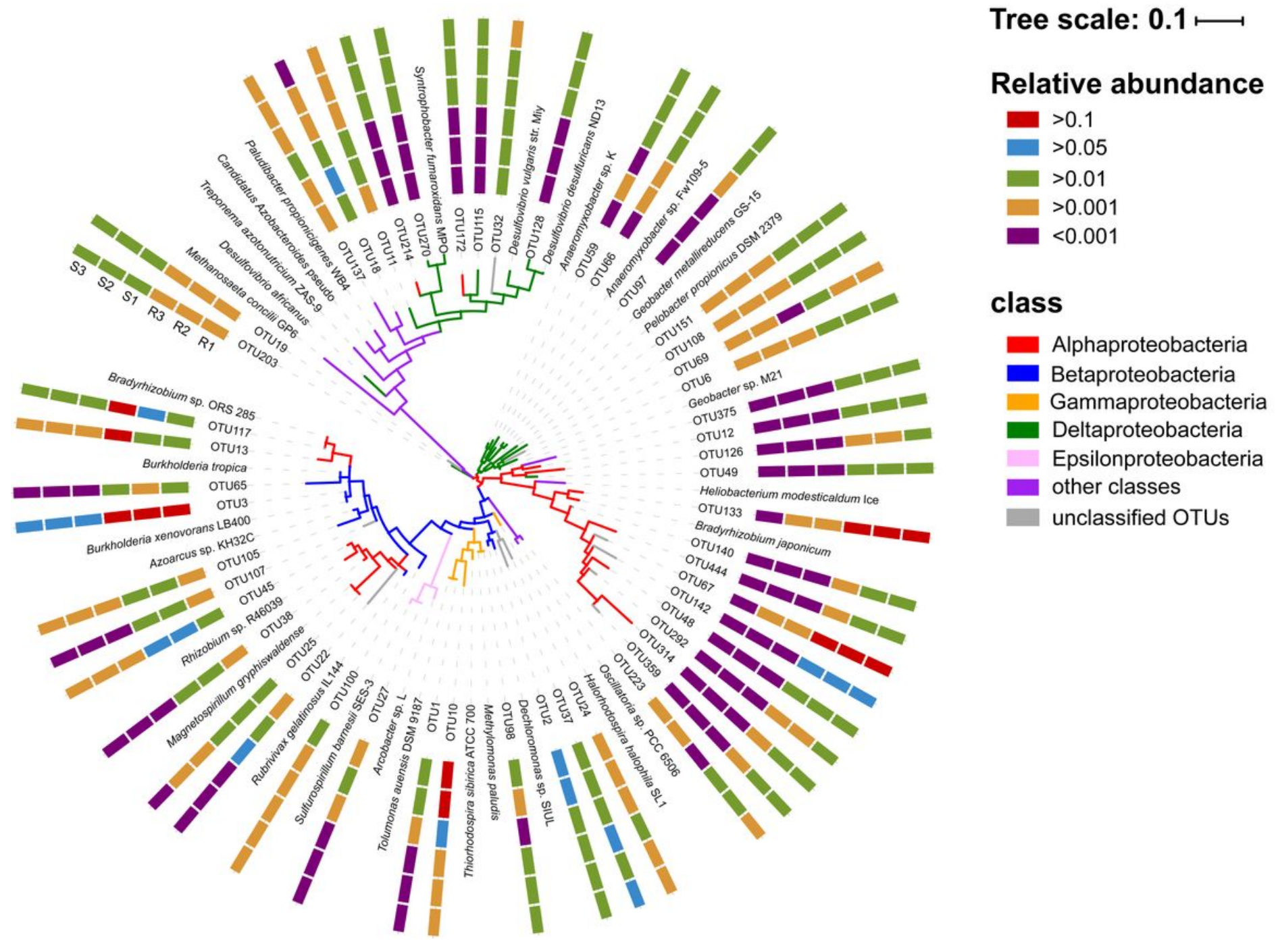

Figure 2

Neighbor-joining tree of the 50 dominant OTUs of all DNA samples in 2016 with their aligned nifH sequences from the FunGene database (bootstrap replications $=1000$ ). Note: The inner phylogenetic tree depicts the evolutionary relationship of the 50 dominant OTUs, and the outer little rectangles represent the variances of the relative abundances of these dominant OTUs during rice growth. Different colors of the inner lines represent the classes of the OTUs and their aligned nifH sequences. The color of each outer little rectangle represents the percentage of each sample in respect of the total. S1: soil DNA samples at the tillering stage; S2: soil DNA samples at the heading stage; S3: soil DNA samples at the mature stage; R1: root DNA samples at the tillering stage; R2: root DNA samples at the heading stage; R3: root DNA samples at the mature stage. 


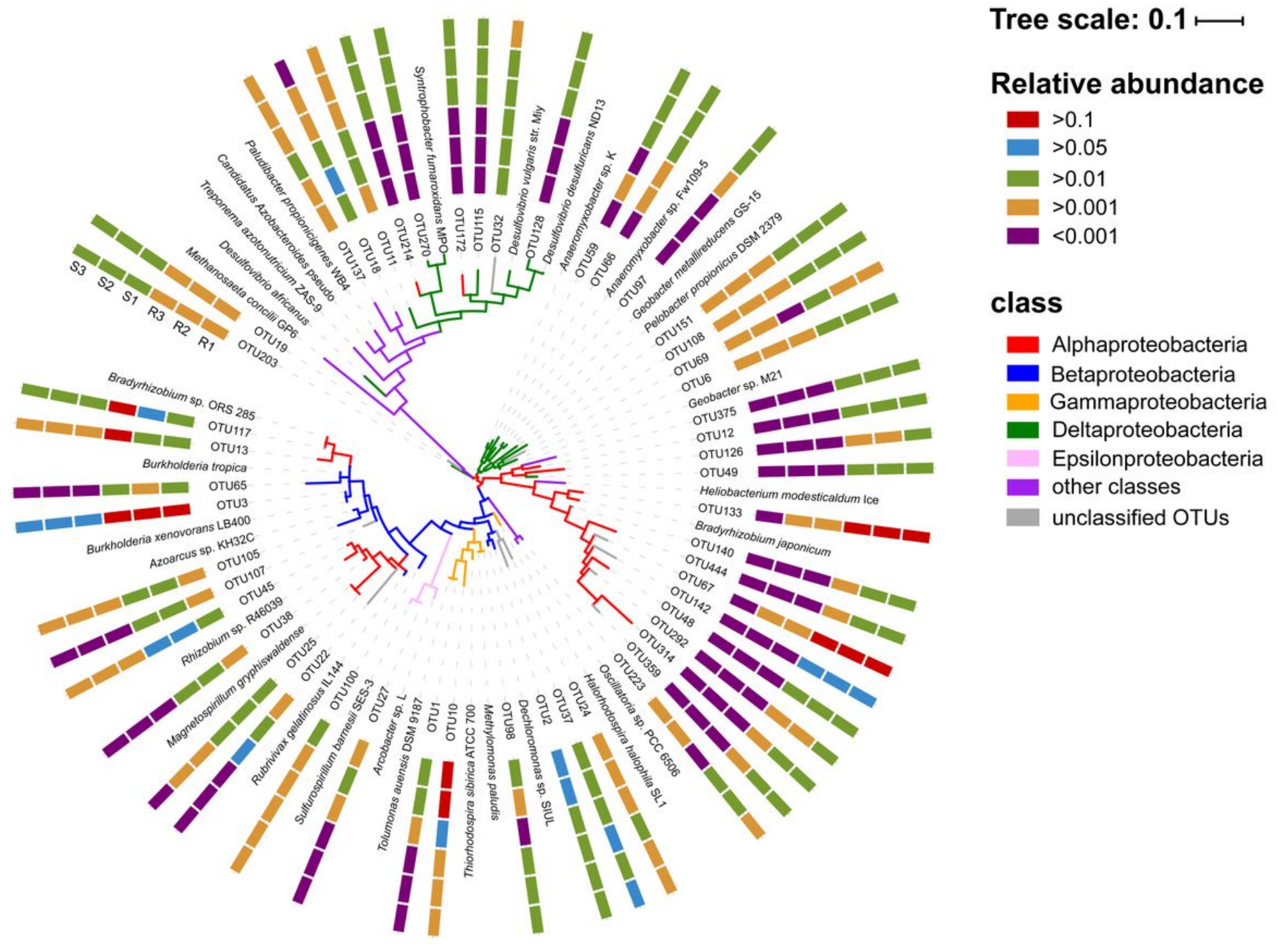

Figure 2

Neighbor-joining tree of the 50 dominant OTUs of all DNA samples in 2016 with their aligned nifH sequences from the FunGene database (bootstrap replications $=1000$ ). Note: The inner phylogenetic tree depicts the evolutionary relationship of the 50 dominant OTUs, and the outer little rectangles represent the variances of the relative abundances of these dominant OTUs during rice growth. Different colors of the inner lines represent the classes of the OTUs and their aligned nifH sequences. The color of each outer little rectangle represents the percentage of each sample in respect of the total. S1: soil DNA samples at the tillering stage; S2: soil DNA samples at the heading stage; S3: soil DNA samples at the mature stage; R1: root DNA samples at the tillering stage; R2: root DNA samples at the heading stage; R3: root DNA samples at the mature stage. 
a

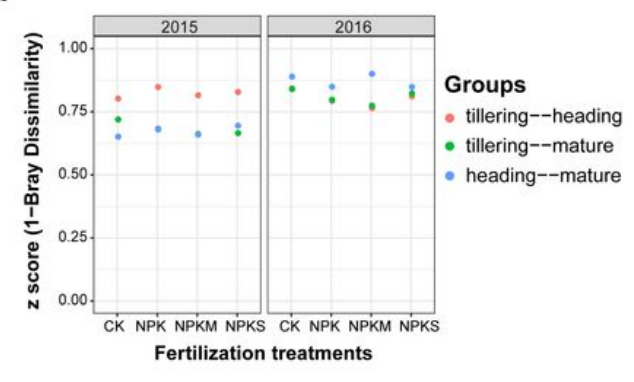

b

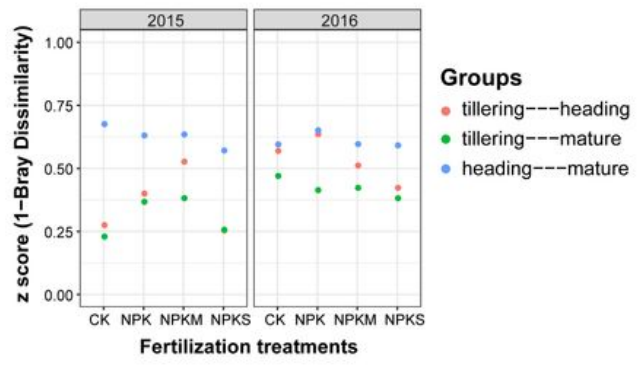

C
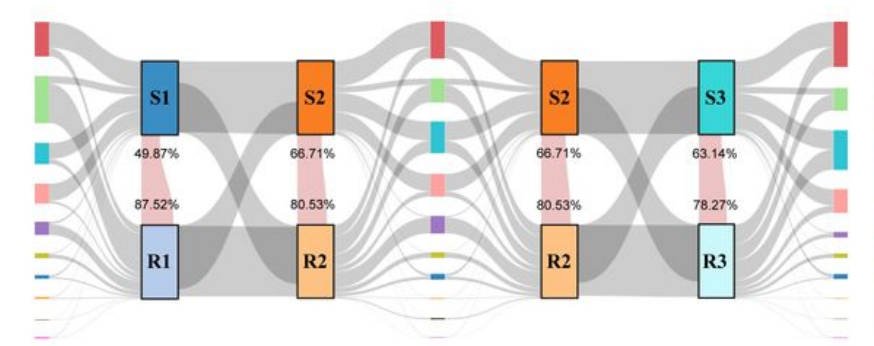

Class

others

Betaproteobacteria

Alphaproteobacteria

Deltaproteobacteria

- Gammaproteobacteria

Bacteroidia

Clostridia

Spirochaetia

Epsilonproteobacteria

Chlorobia

\section{d}
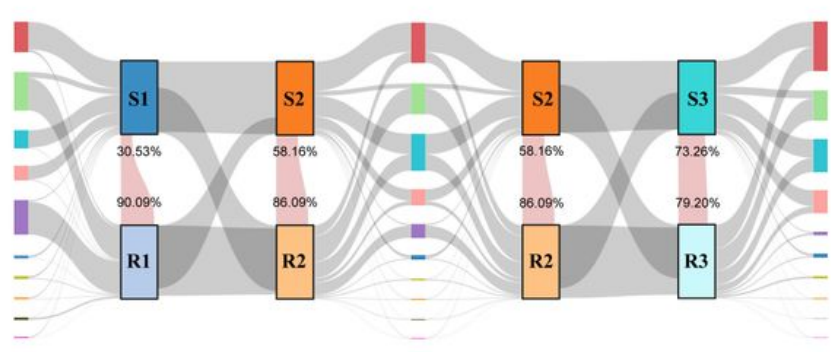

Class

others

Betaproteobacteria

Alphaproteobacteria

Deltaproteobacteria

Gammaproteobacteria

- Clostridia

- Bacteroidia

- Spirochaetia

Epsilonproteobacteria

- Chlorobia

e

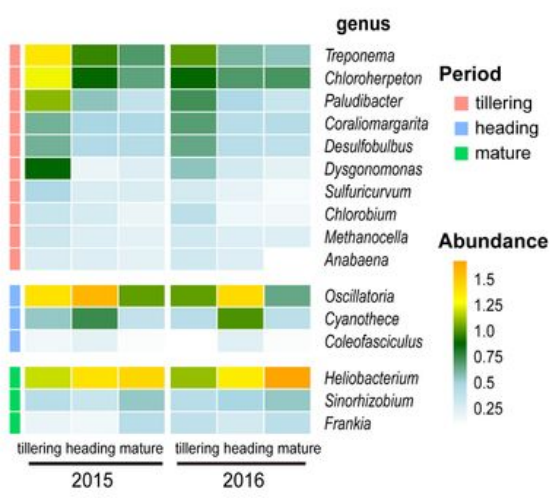

f

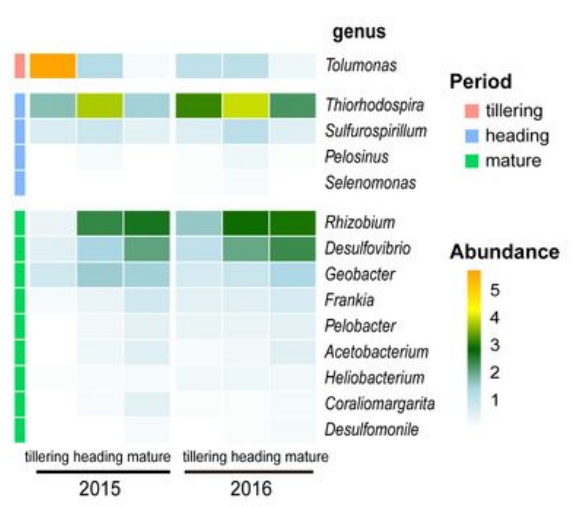

Figure 3

Scatter plots of the mean pairwise z-scores for similarity, computed as (1-Bray Curtis dissimilarity), between growth periods in rhizosphere soil (a) and rice roots (b) for the 2015 and 2016 DNA samples. Sankey plots of associated diazotrophic flow at the class level during rice growth in 2016 (c) and 2015 (d). Color bars indicate different classes, and the heights of bars indicate the relative number of classes. Pink flows indicate variations in abundance of shared OTUs between soil and root samples at the same sampling point. Heatmap plots showing changes in the relative abundances of discriminating genera throughout rice growth in rhizosphere soil (e) and rice roots (f). 
a

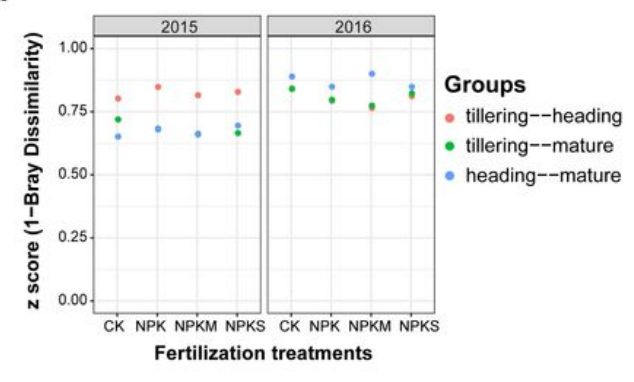

b

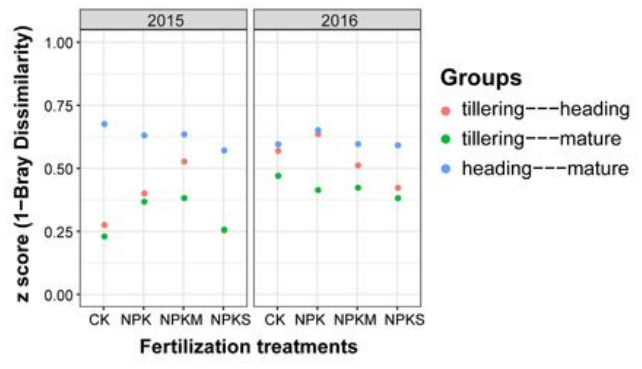

C
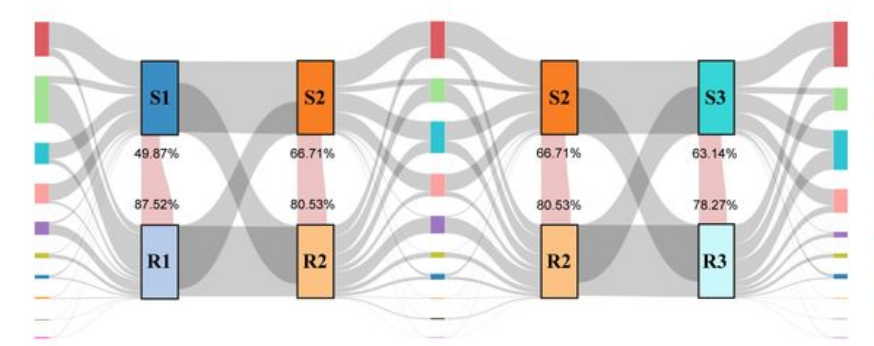

Class

others

Betaproteobacteria

Alphaproteobacteria

Deltaproteobacteria

- Gammaproteobacteria

Bacteroidia

Clostridia

Spirochaetia

Epsilonproteobacteria

Chlorobia

\section{d}
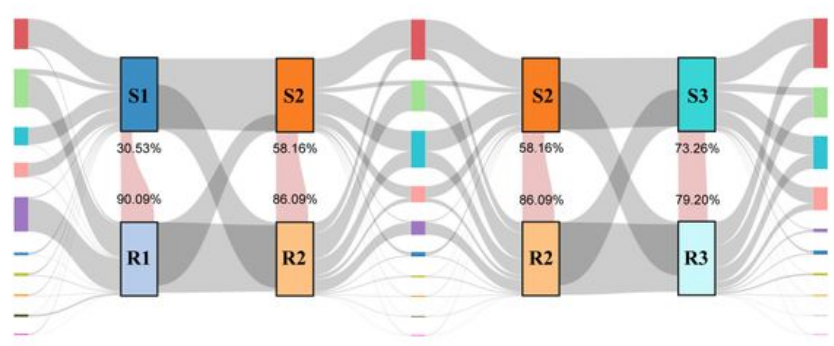

Class

others

Betaproteobacteria

Alphaproteobacteria

Deltaproteobacteria

Gammaproteobacteria

Clostridia

Bacteroidia

- Spirochaetia

Epsilonproteobacteria

Chlorobia

e

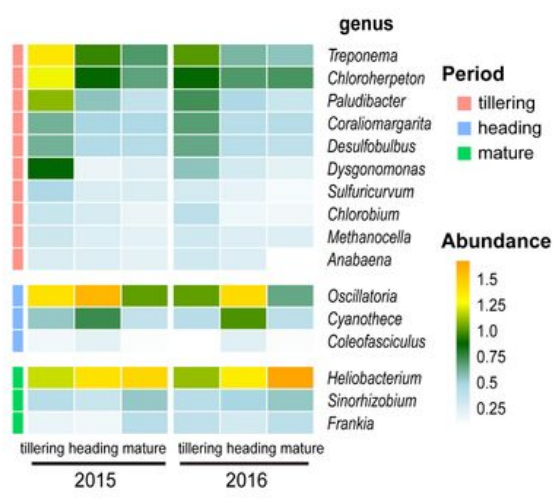

f

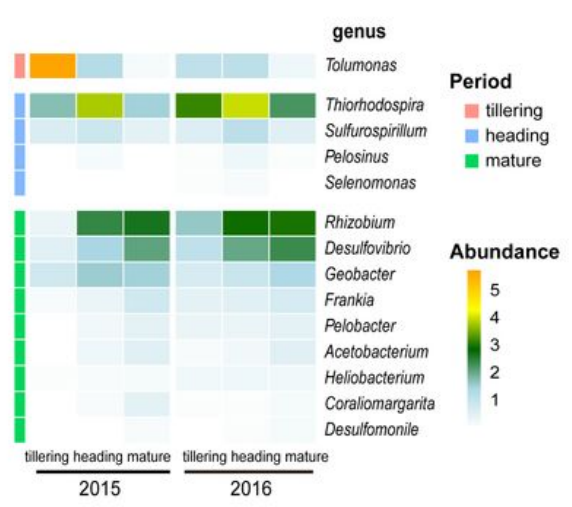

Figure 3

Scatter plots of the mean pairwise z-scores for similarity, computed as (1-Bray Curtis dissimilarity), between growth periods in rhizosphere soil (a) and rice roots (b) for the 2015 and 2016 DNA samples. Sankey plots of associated diazotrophic flow at the class level during rice growth in 2016 (c) and 2015 (d). Color bars indicate different classes, and the heights of bars indicate the relative number of classes. Pink flows indicate variations in abundance of shared OTUs between soil and root samples at the same sampling point. Heatmap plots showing changes in the relative abundances of discriminating genera throughout rice growth in rhizosphere soil (e) and rice roots (f). 
a

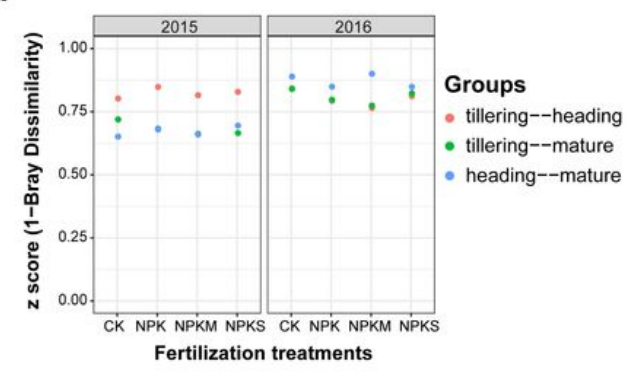

b

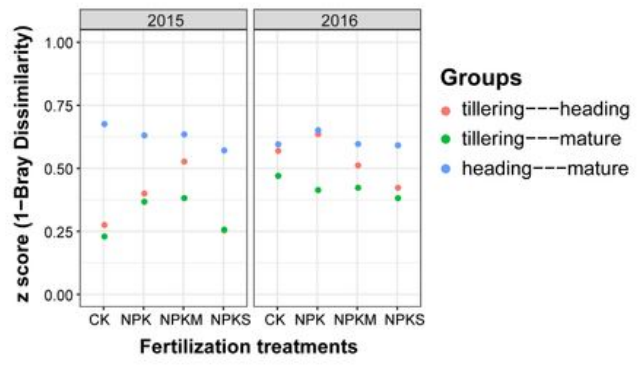

C
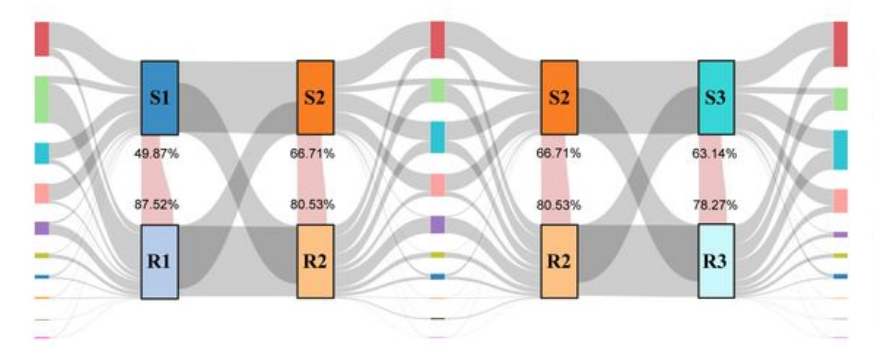

Class

others

Betaproteobacteria

Alphaproteobacteria

Deltaproteobacteria

- Gammaproteobacteria

Bacteroidia

Clostridia

Spirochaetia

Epsilonproteobacteria

Chlorobia

\section{d}
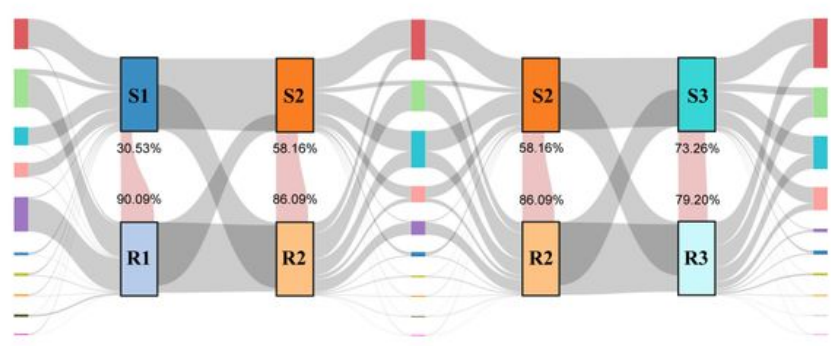

Class

others

Betaproteobacteria

Alphaproteobacteria

Deltaproteobacteria

Gammaproteobacteria

Clostridia

Bacteroidia

- Spirochaetia

Epsilonproteobacteria

Chlorobia

e

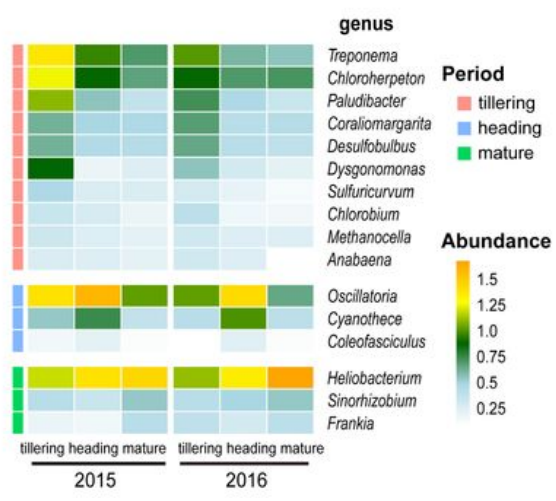

f

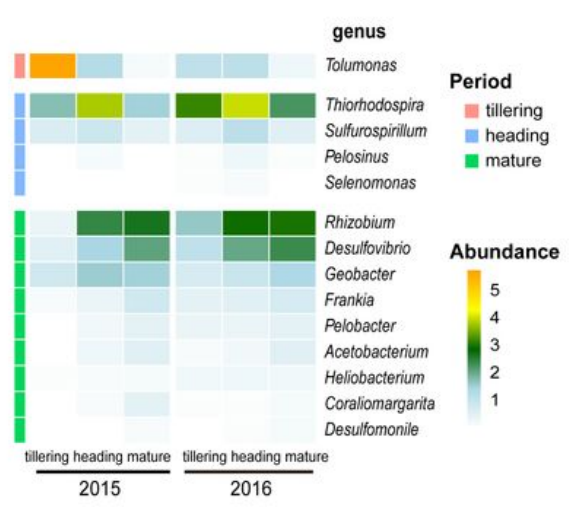

Figure 3

Scatter plots of the mean pairwise z-scores for similarity, computed as (1-Bray Curtis dissimilarity), between growth periods in rhizosphere soil (a) and rice roots (b) for the 2015 and 2016 DNA samples. Sankey plots of associated diazotrophic flow at the class level during rice growth in 2016 (c) and 2015 (d). Color bars indicate different classes, and the heights of bars indicate the relative number of classes. Pink flows indicate variations in abundance of shared OTUs between soil and root samples at the same sampling point. Heatmap plots showing changes in the relative abundances of discriminating genera throughout rice growth in rhizosphere soil (e) and rice roots (f). 
a

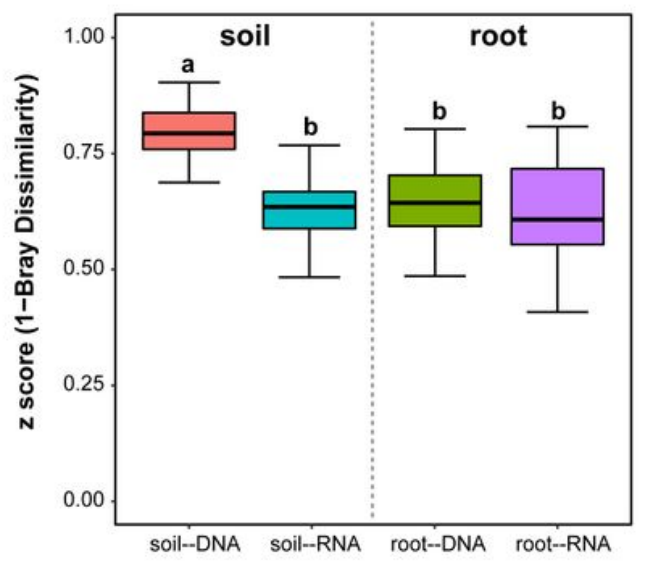

C

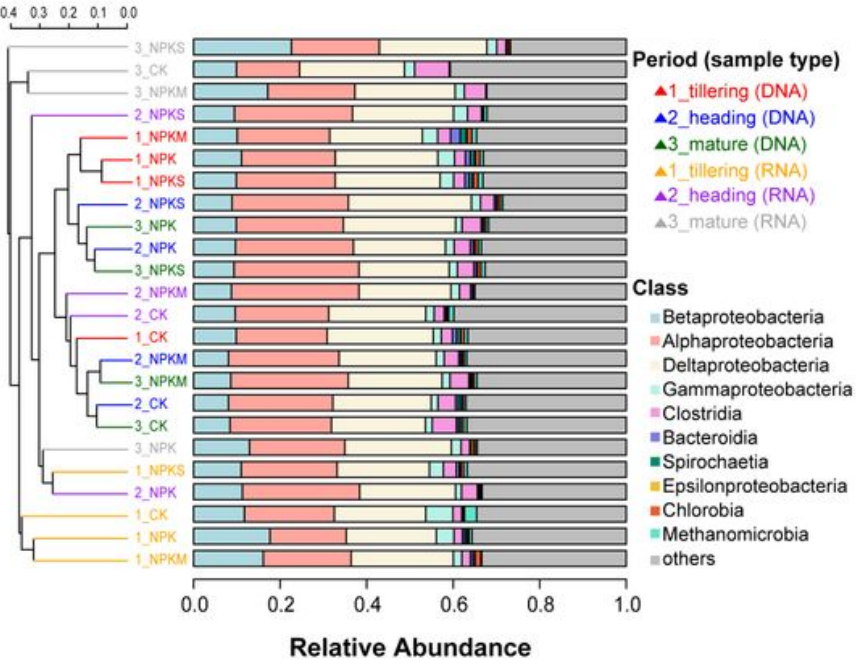

b

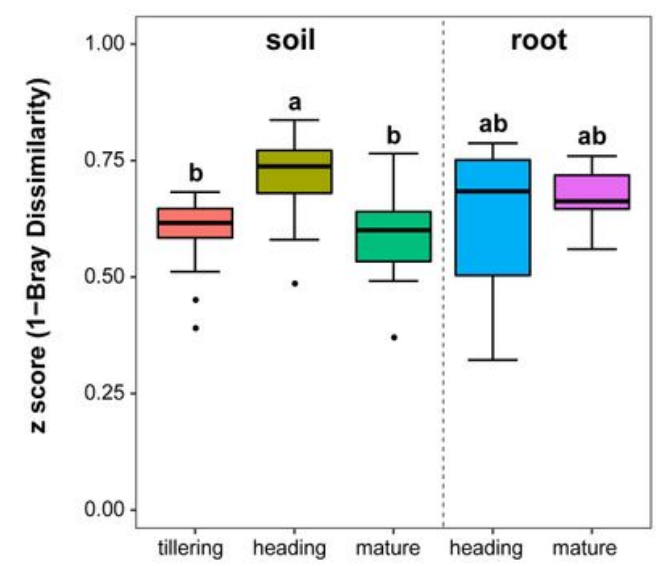

d

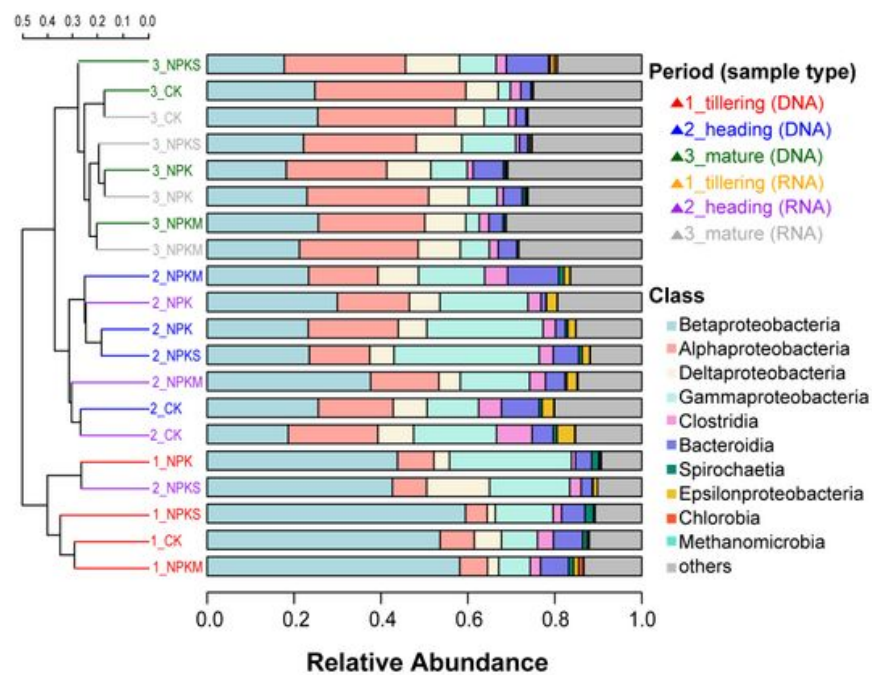

\section{Figure 4}

Similarities in the between-community variation of diazotrophs in the soil DNA, root DNA, soil RNA and root RNA libraries (a) in 2016. Similarities of the diazotrophic communities between the DNA samples and their corresponding RNA samples among three growth periods in 2016 (b). Total and active diazotrophic community composition of the rhizosphere soil (c) and rice root (d) samples in 2016 at the class level. Note: The cluster tree was based on Bray-Curtis similarities at the OTU level. Different lowercase letters indicate significant differences between libraries $(P<0.05$, Tukey's HSD test). 
a

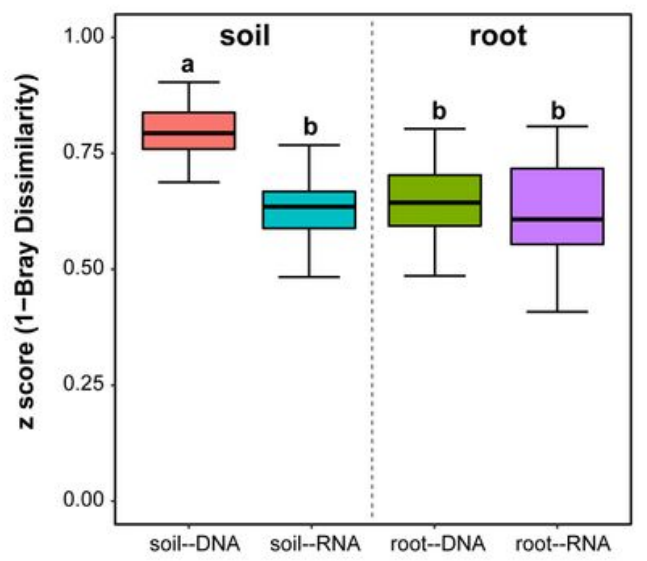

C

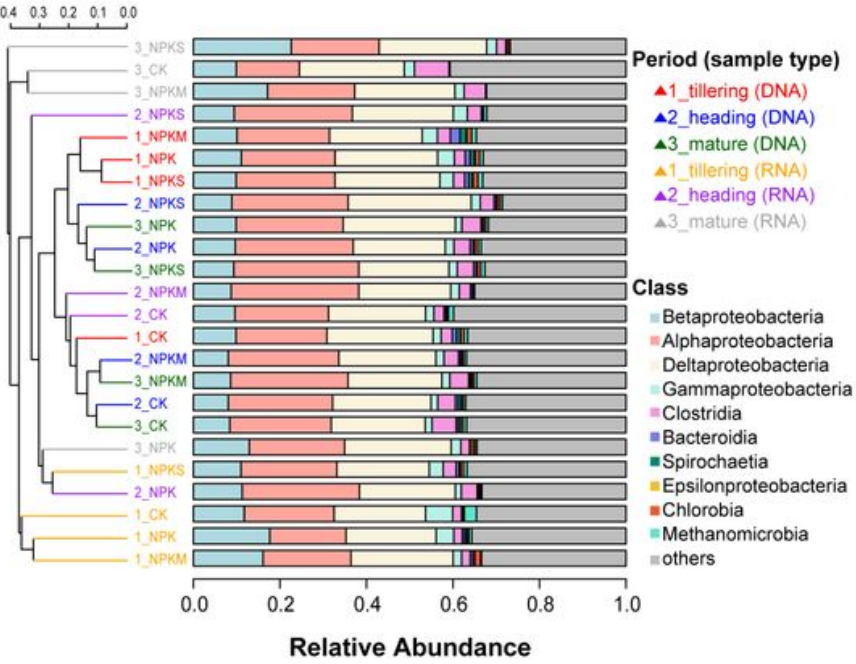

b

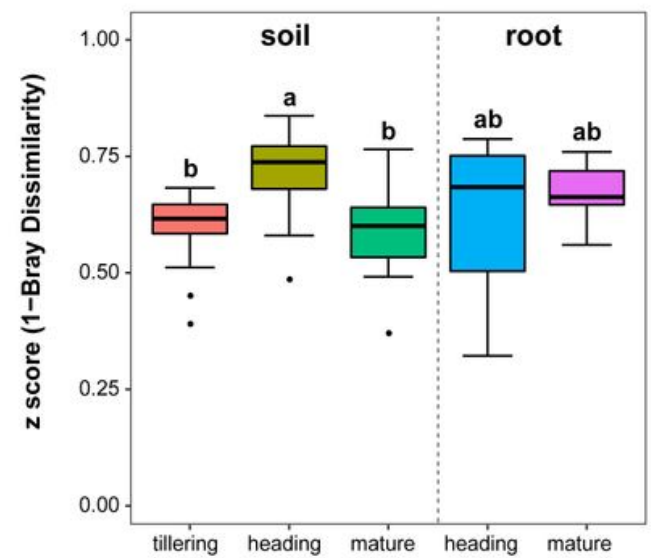

d

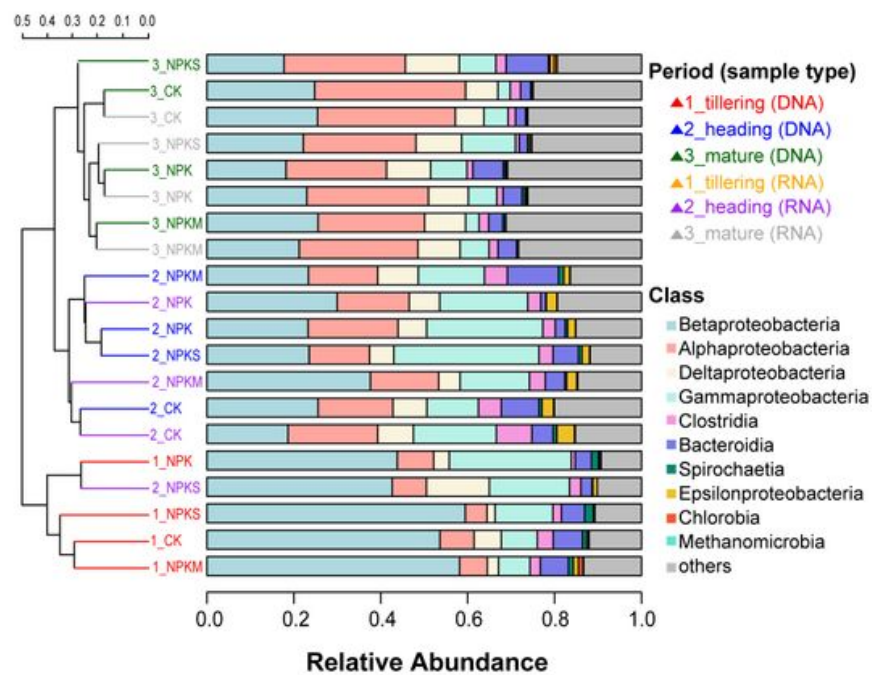

\section{Figure 4}

Similarities in the between-community variation of diazotrophs in the soil DNA, root DNA, soil RNA and root RNA libraries (a) in 2016. Similarities of the diazotrophic communities between the DNA samples and their corresponding RNA samples among three growth periods in 2016 (b). Total and active diazotrophic community composition of the rhizosphere soil (c) and rice root (d) samples in 2016 at the class level. Note: The cluster tree was based on Bray-Curtis similarities at the OTU level. Different lowercase letters indicate significant differences between libraries $(P<0.05$, Tukey's HSD test). 
a

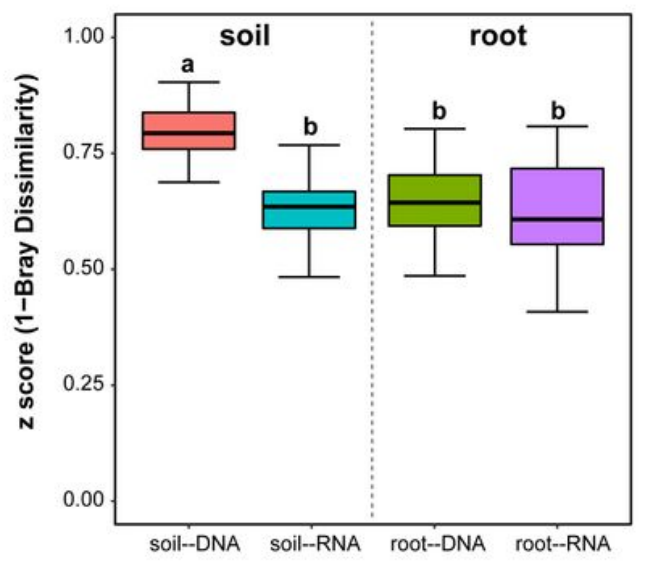

C

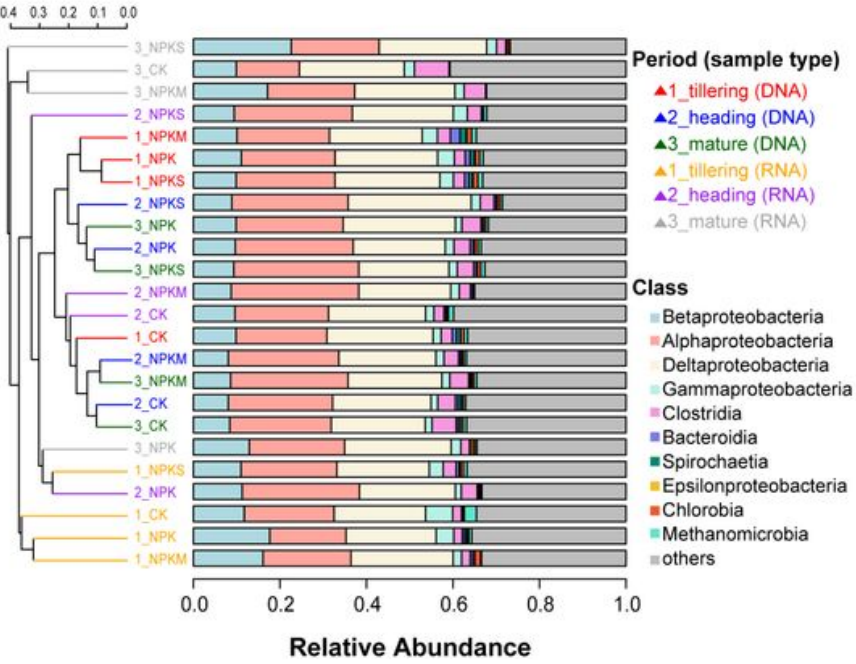

b

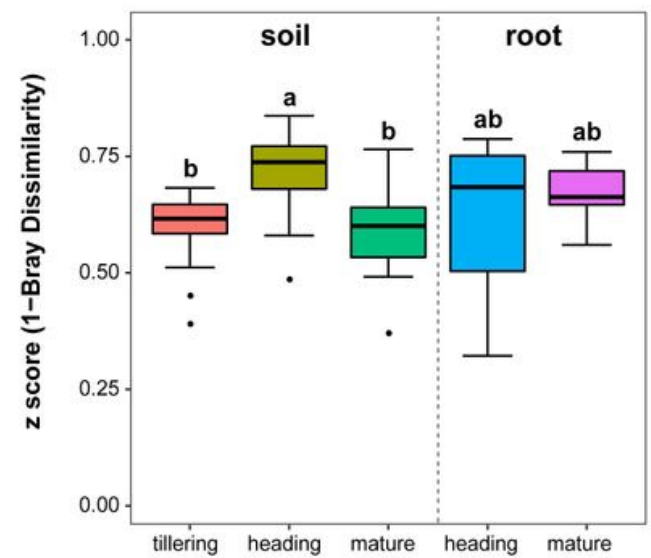

d

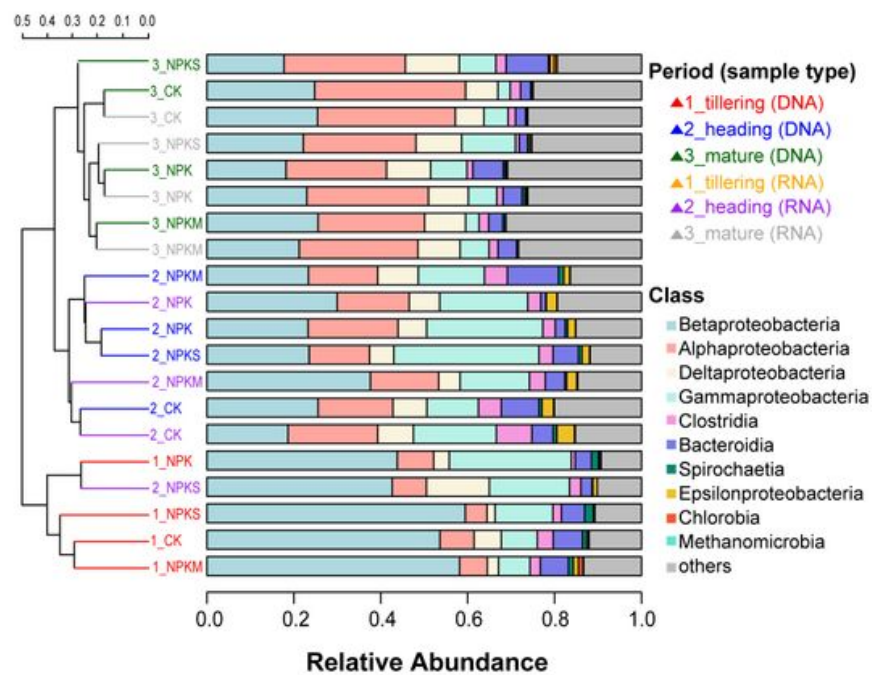

\section{Figure 4}

Similarities in the between-community variation of diazotrophs in the soil DNA, root DNA, soil RNA and root RNA libraries (a) in 2016. Similarities of the diazotrophic communities between the DNA samples and their corresponding RNA samples among three growth periods in 2016 (b). Total and active diazotrophic community composition of the rhizosphere soil (c) and rice root (d) samples in 2016 at the class level. Note: The cluster tree was based on Bray-Curtis similarities at the OTU level. Different lowercase letters indicate significant differences between libraries $(P<0.05$, Tukey's HSD test). 


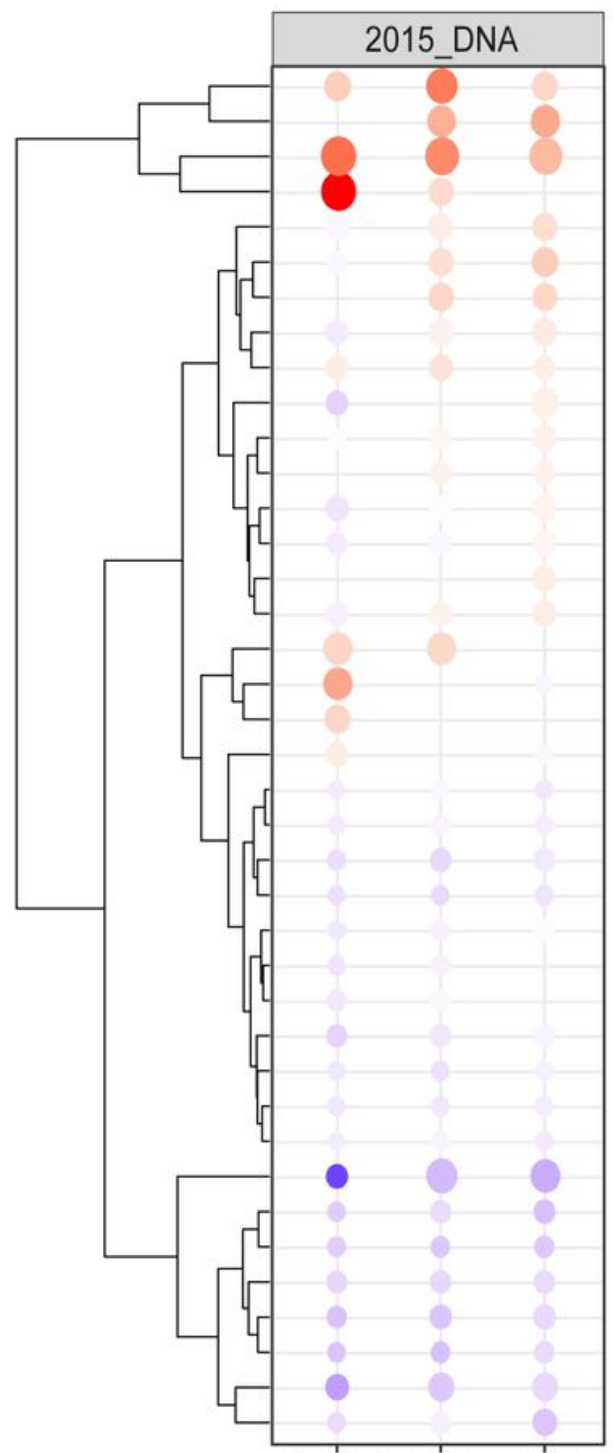

tillering heading mature

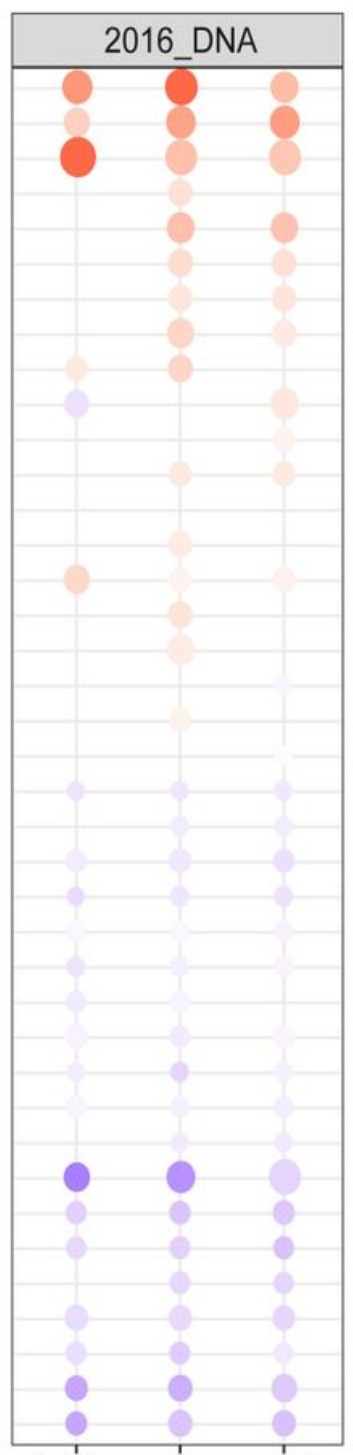

tillering heading mature

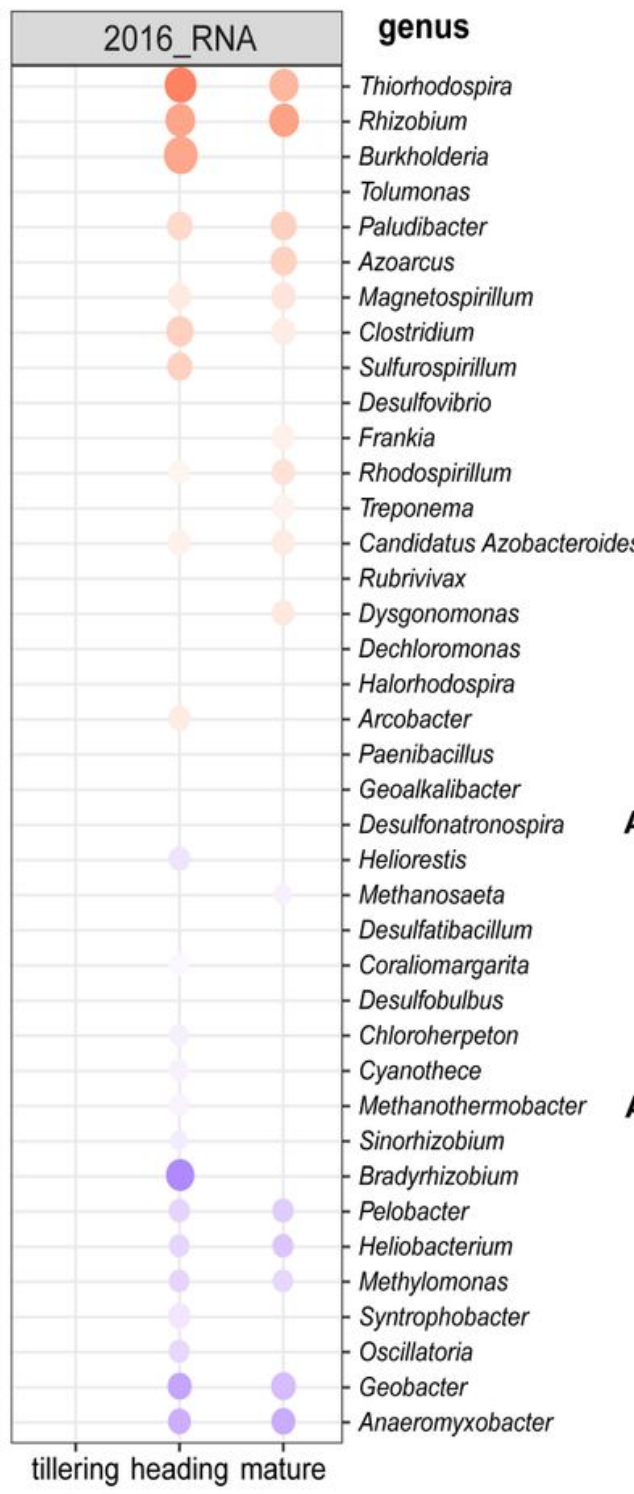

Abundance

2

4

6

Abundance difference

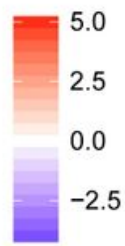

Figure 5

Bubble plot showing the relative abundance of the dominant genera (relative abundance $>0.1 \%$ ) in root DNA and RNA samples during three growth periods. Note: The cluster tree was based on the differences of the relative abundance in root and soil samples at the genus level using the complete linkage method. The size of each bubble represents the square root of the relative abundance of each genus in the root sample. The color of each bubble represents the difference between the square root of relative abundance of each genus in the root and in the rice sample. Red bubbles indicate genera which are abundant in the roots, and blue bubbles indicate genera which are abundant in the rhizosphere soil. Insignificant differences are not shown $(P>0.05)$. 


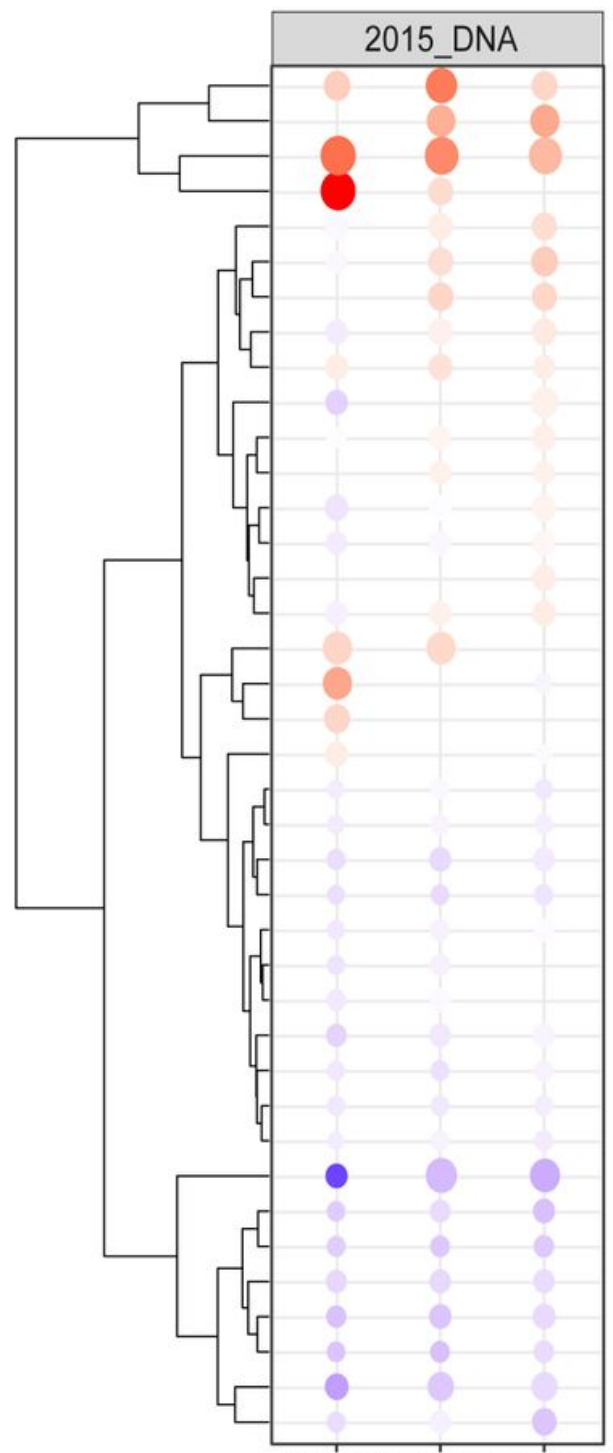

tillering heading mature

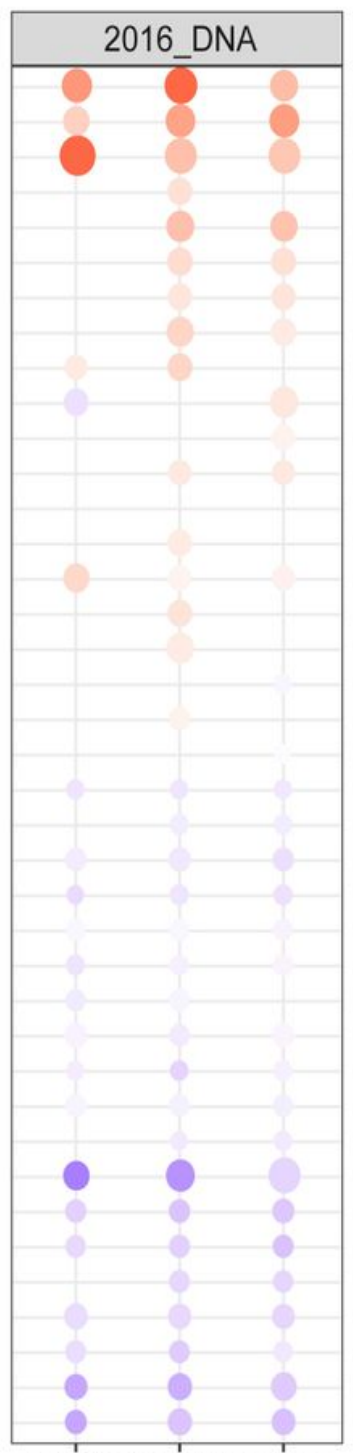

tillering heading mature

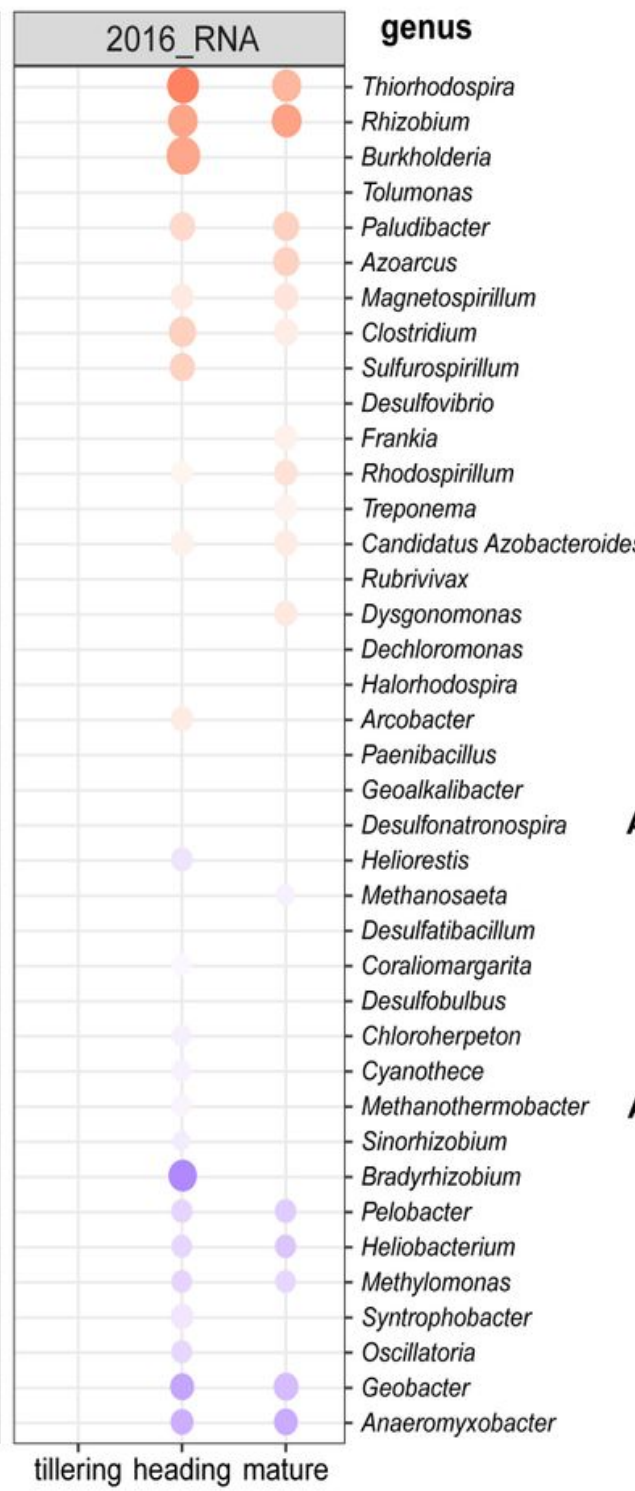

Abundance

2

4

6

Abundance difference

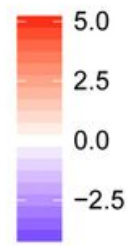

Figure 5

Bubble plot showing the relative abundance of the dominant genera (relative abundance $>0.1 \%$ ) in root DNA and RNA samples during three growth periods. Note: The cluster tree was based on the differences of the relative abundance in root and soil samples at the genus level using the complete linkage method. The size of each bubble represents the square root of the relative abundance of each genus in the root sample. The color of each bubble represents the difference between the square root of relative abundance of each genus in the root and in the rice sample. Red bubbles indicate genera which are abundant in the roots, and blue bubbles indicate genera which are abundant in the rhizosphere soil. Insignificant differences are not shown $(P>0.05)$. 


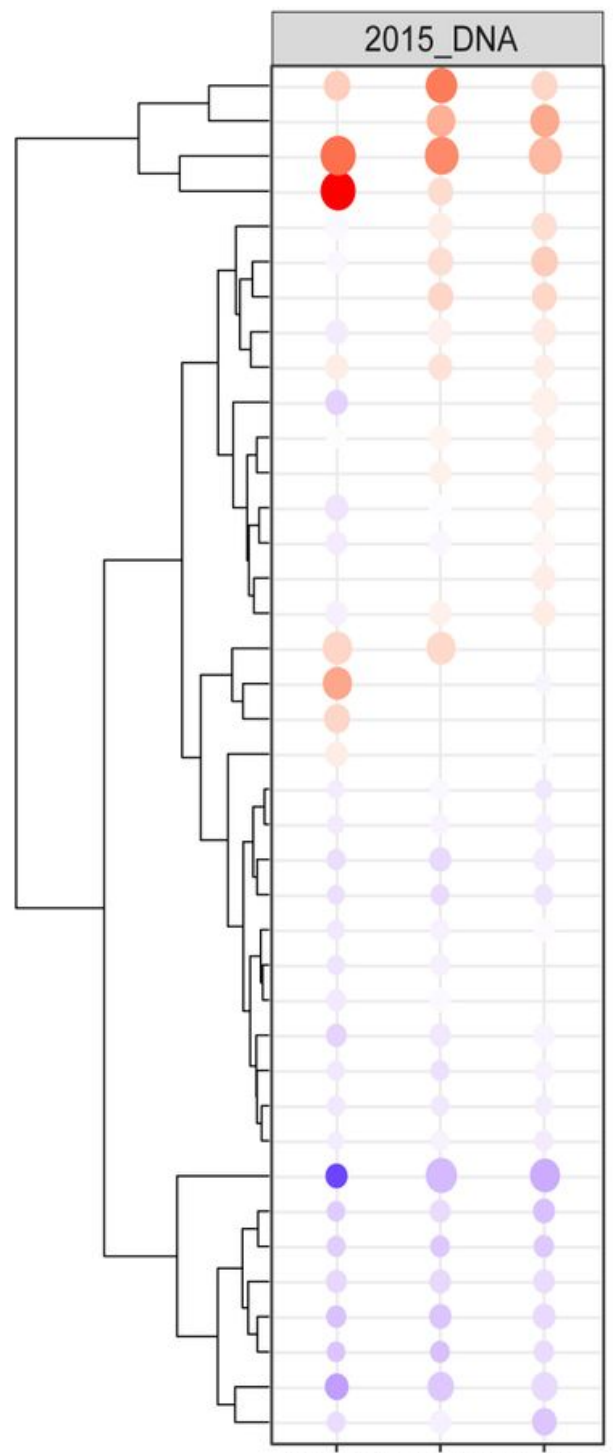

tillering heading mature

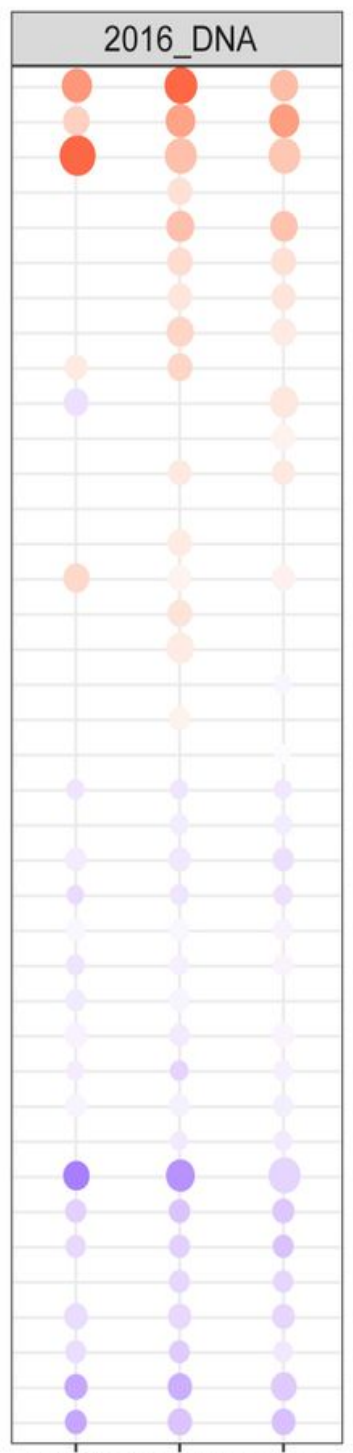

tillering heading mature

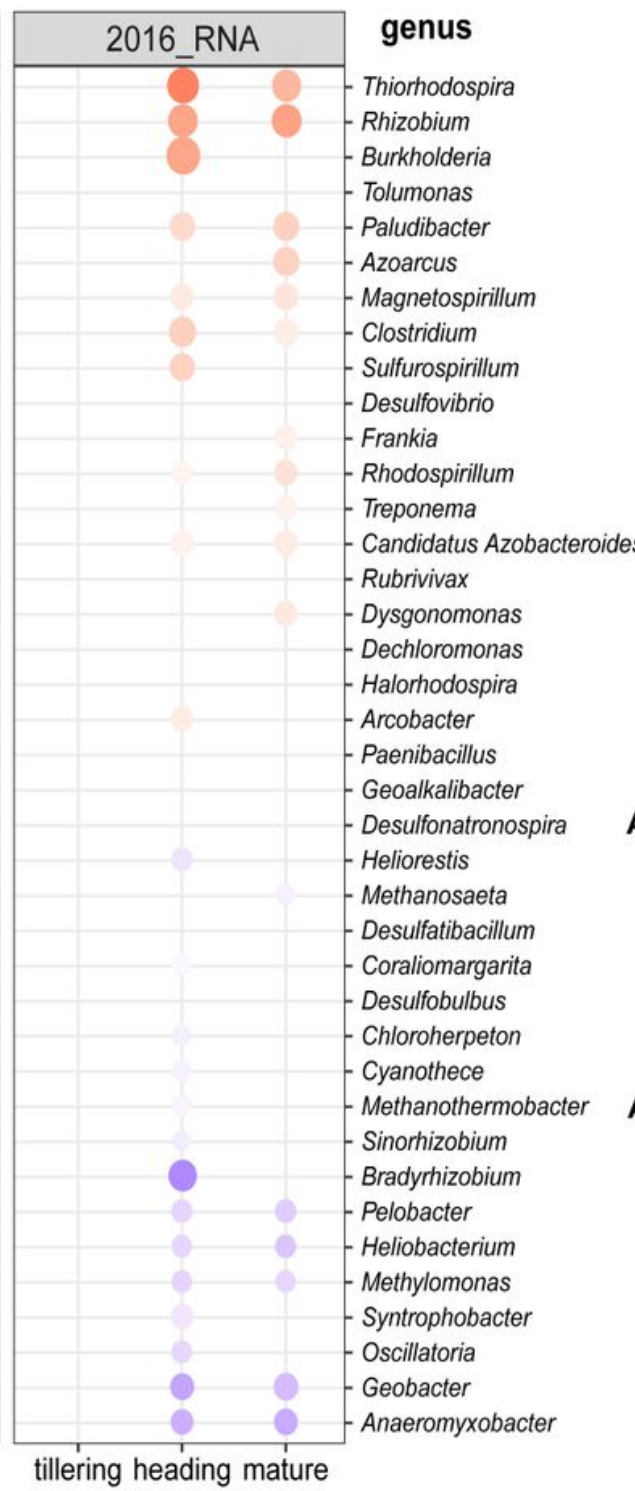

Abundance

2

4

6

Abundance difference

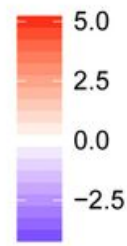

Figure 5

Bubble plot showing the relative abundance of the dominant genera (relative abundance $>0.1 \%$ ) in root DNA and RNA samples during three growth periods. Note: The cluster tree was based on the differences of the relative abundance in root and soil samples at the genus level using the complete linkage method. The size of each bubble represents the square root of the relative abundance of each genus in the root sample. The color of each bubble represents the difference between the square root of relative abundance of each genus in the root and in the rice sample. Red bubbles indicate genera which are abundant in the roots, and blue bubbles indicate genera which are abundant in the rhizosphere soil. Insignificant differences are not shown $(P>0.05)$. 


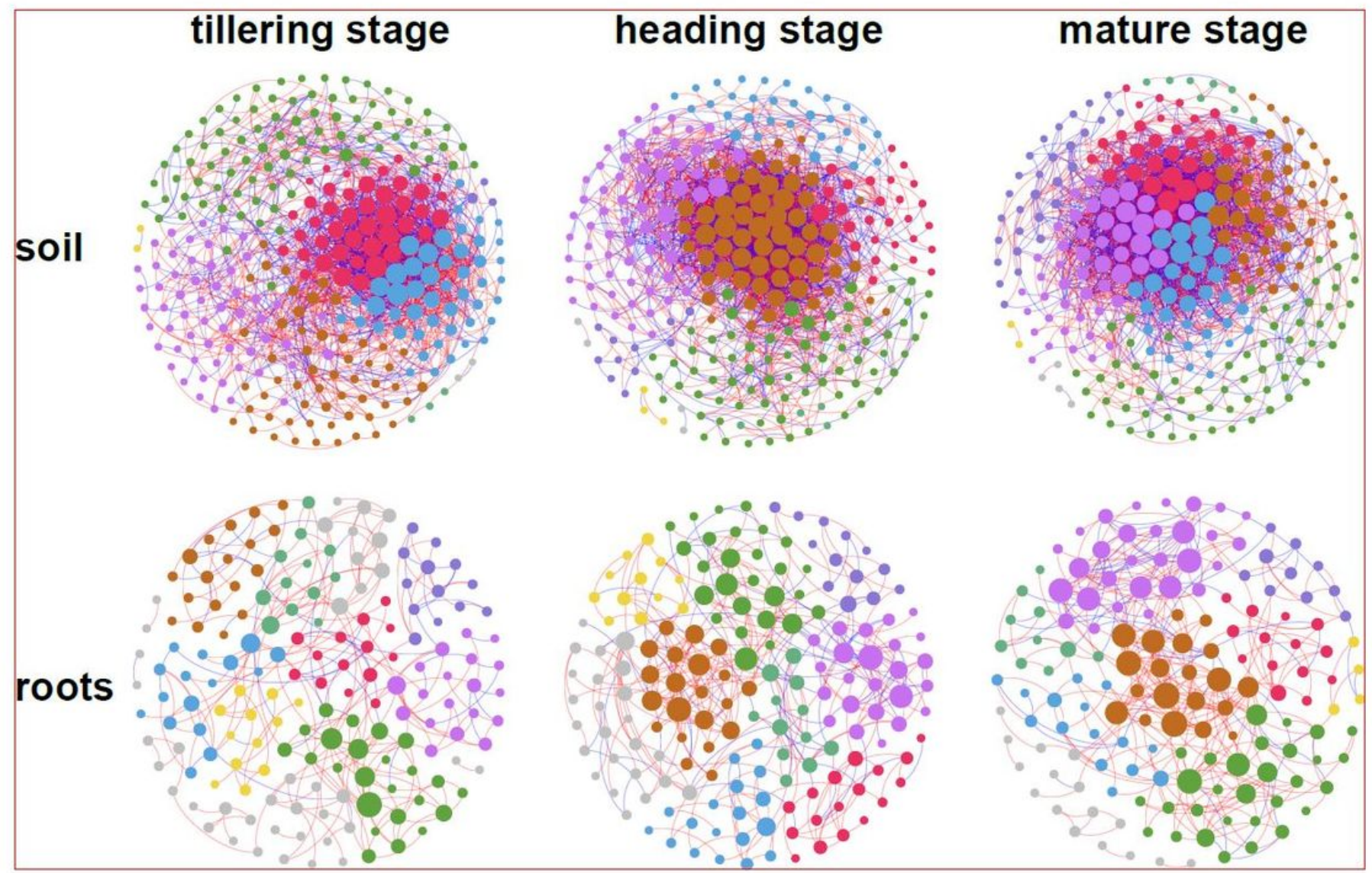

Figure 6

The co-occurrence networks of total root-associated diazotrophs in 2016. Points (nodes) represent different OTUs. Note: Red solid lines show strong (Spearman's correlation coefficient $r \otimes 0.65)$ and significant $(P<0.01)$ positive correlations. Blue solid lines show strong (Spearman's correlation coefficient $r<-0.65)$ and significant $(P<0.01)$ negative correlations. The size of each point is the node's weighted degree. 


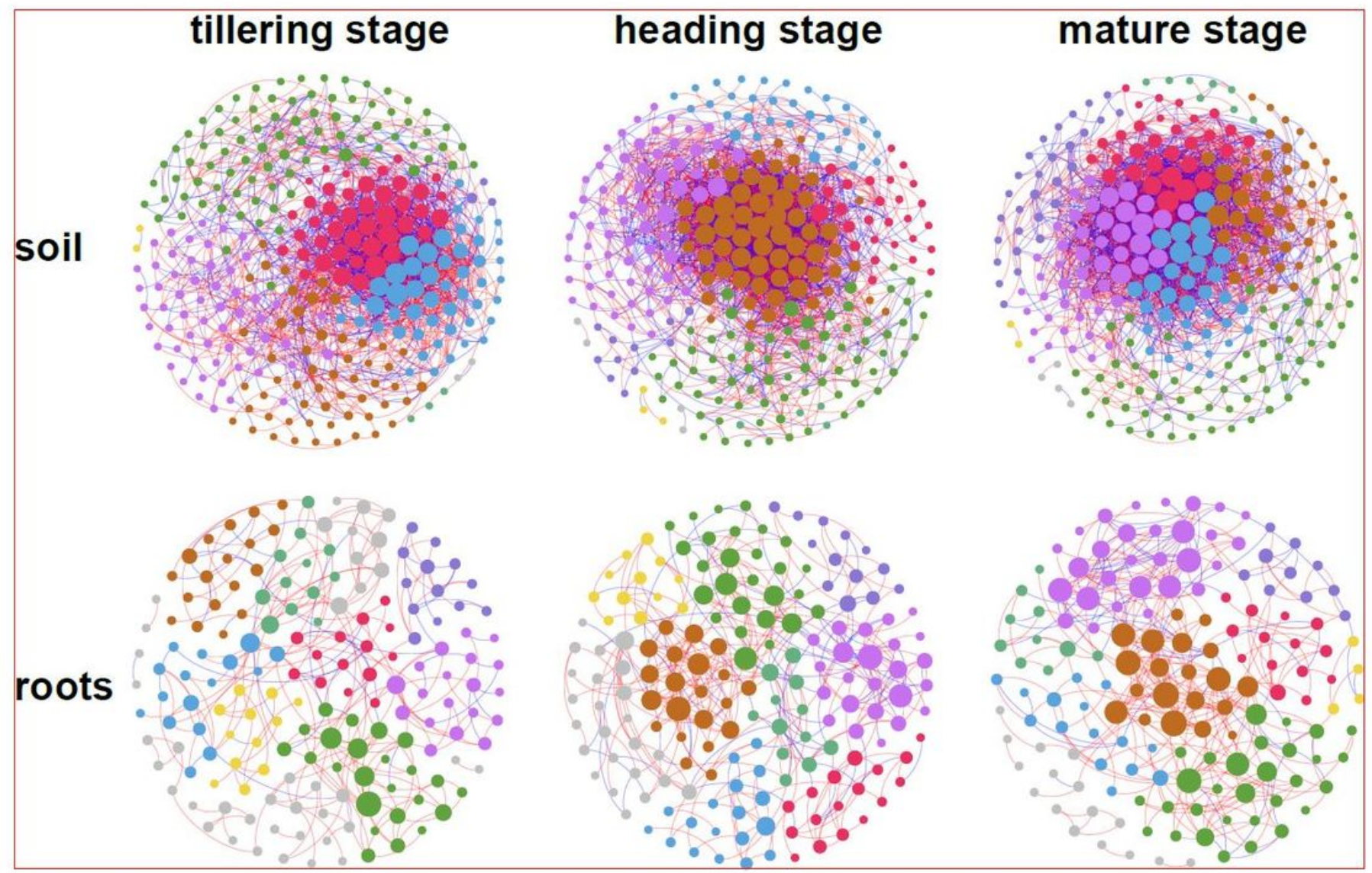

Figure 6

The co-occurrence networks of total root-associated diazotrophs in 2016. Points (nodes) represent different OTUs. Note: Red solid lines show strong (Spearman's correlation coefficient $r \otimes 0.65)$ and significant $(P<0.01)$ positive correlations. Blue solid lines show strong (Spearman's correlation coefficient $r<-0.65)$ and significant $(P<0.01)$ negative correlations. The size of each point is the node's weighted degree. 


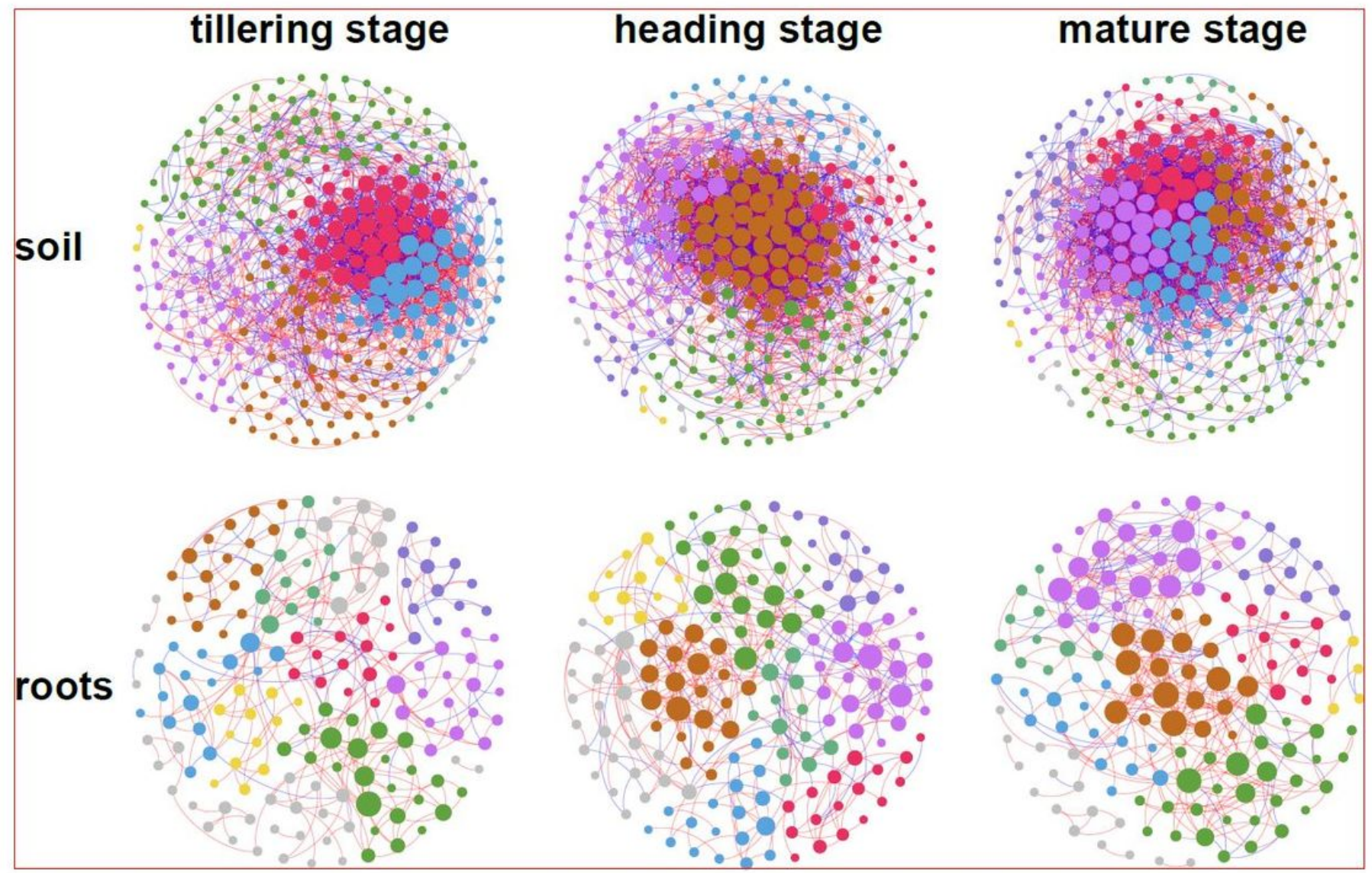

Figure 6

The co-occurrence networks of total root-associated diazotrophs in 2016. Points (nodes) represent different OTUs. Note: Red solid lines show strong (Spearman's correlation coefficient $r \otimes 0.65)$ and significant $(P<0.01)$ positive correlations. Blue solid lines show strong (Spearman's correlation coefficient $r<-0.65)$ and significant $(P<0.01)$ negative correlations. The size of each point is the node's weighted degree.

\section{Supplementary Files}

This is a list of supplementary files associated with this preprint. Click to download.

- Additionalfile23.xlsx

- Additionalfile23.xlsx

- Additionalfile23.xIsx

- Additionalfile22.pdf

- Additionalfile22.pdf

- Additionalfile22.pdf

- Additionalfile20.docx

- Additionalfile20.docx

- Additionalfile20.docx

- Additionalfile21.pdf 
- Additionalfile21.pdf

- Additionalfile21.pdf

- Additionalfile19.pdf

- Additionalfile19.pdf

- Additionalfile19.pdf

- Additionalfile18.docx

- Additionalfile18.docx

- Additionalfile18.docx

- Additionalfile17.xIsx

- Additionalfile17.xIsx

- Additionalfile17.xlsx

- Additionalfile16.docx

- Additionalfile16.docx

- Additionalfile16.docx

- Additionalfile15.xlsx

- Additionalfile15.xlsx

- Additionalfile15.xlsx

- Additionalfile14.pdf

- Additionalfile14.pdf

- Additionalfile14.pdf

- Additionalfile13.docx

- Additionalfile13.docx

- Additionalfile13.docx

- Additionalfile12.pdf

- Additionalfile12.pdf

- Additionalfile12.pdf

- Additionalfile11.pdf

- Additionalfile11.pdf

- Additionalfile11.pdf

- Additionalfile10.pdf

- Additionalfile10.pdf

- Additionalfile10.pdf

- Additionalfile9.docx

- Additionalfile9.docx

- Additionalfile9.docx

- Additionalfile8.pdf

- Additionalfile8.pdf

- Additionalfile8.pdf

- Additionalfile7.xlsx

- Additionalfile7.xlsx 
- Additionalfile7.xlsx

- Additionalfile6.xIsx

- Additionalfile6.xlsx

- Additionalfile6.xlsx

- Additionalfile5.pdf

- Additionalfile5.pdf

- Additionalfile5.pdf

- Additionalfile4.docx

- Additionalfile4.docx

- Additionalfile4.docx

- Additionalfile3.docx

- Additionalfile3.docx

- Additionalfile3.docx

- Additionalfile2.docx

- Additionalfile2.docx

- Additionalfile2.docx

- Additionalfile1.docx

- Additionalfile1.docx

- Additionalfile1.docx 